Provided for non-commercial research and education use. Not for reproduction, distribution or commercial use.

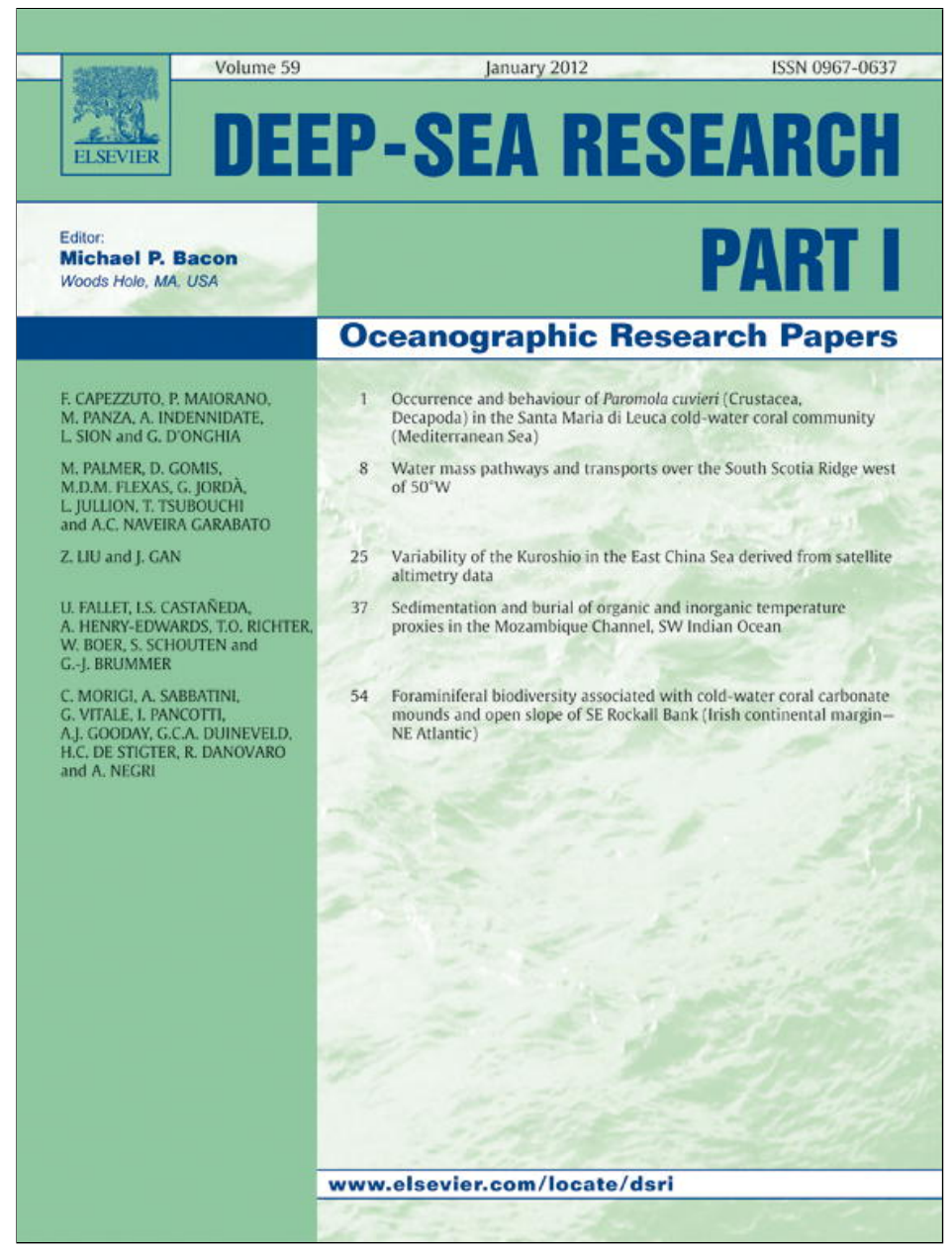

(This is a sample cover image for this issue. The actual cover is not yet available at this time.)

This article appeared in a journal published by Elsevier. The attached copy is furnished to the author for internal non-commercial research and education use, including for instruction at the authors institution and sharing with colleagues.

Other uses, including reproduction and distribution, or selling or licensing copies, or posting to personal, institutional or third party websites are prohibited.

In most cases authors are permitted to post their version of the article (e.g. in Word or Tex form) to their personal website or institutional repository. Authors requiring further information regarding Elsevier's archiving and manuscript policies are encouraged to visit:

http://www.elsevier.com/copyright 


\title{
Convective mixing in the central Irminger Sea: 2002-2010
}

\author{
M. Femke de Jong ${ }^{\mathrm{b}, *, 1}$, Hendrik M. van Aken ${ }^{\mathrm{b}}$, Kjetil Våge ${ }^{\mathrm{c}}$, Robert S. Pickart ${ }^{\mathrm{a}}$ \\ ${ }^{a}$ Woods Hole Oceanographic Institution, 266 Woods Hole Rd. MS\# 21, Woods Hole, MA 02543-1050, USA \\ ${ }^{\mathrm{b}}$ NIOZ Royal Netherlands Institute of Sea Research, Texel, The Netherlands \\ ${ }^{\mathrm{c}}$ Geophysical Institute, University of Bergen, Bergen, Norway
}

\section{A R T I C L E I N F O}

\section{Article history:}

Received 6 July 2011

Received in revised form

5 January 2012

Accepted 7 January 2012

Available online 17 January 2012

Keywords:

Deep convection

Convective mixing

Irminger sea

Subpolar Gyre

North Atlantic Ocean

Deep water formation

Mixed layer depth

Labrador sea water

Mooring data

Moored profilers

Floats

\begin{abstract}
A B S T R A C T
A near-continuous time series of 8 years of daily hydrographic profiles, recorded between fall 2002 and summer 2010 by moorings located in the central Irminger Sea, is presented. This record shows that convective mixing down to $400 \mathrm{~m}$ depth occurs in most winters. Under favorable conditions, convective mixing is seen to reach much deeper. During the cold winter of 2007-2008 mixed layers reached depths of $1 \mathrm{~km}$. In the subsequent, more moderate winter of 2008-2009, a stronger preconditioning of the Irminger Gyre led to mixed layers down to $800 \mathrm{~m}$ depth. The convectively formed waters in the Irminger Sea are more saline and warmer than those formed in the Labrador Sea, but potential vorticity is reduced to $0.710^{-12} \mathrm{~m}^{-1} \mathrm{~s}^{-1}$ in March 2009. Following the local wintertime convection of 2007-2008, columns of relatively fresh water were seen to arrive in the Irminger Sea in spring 2008. A comparison with float data suggests that this water mass was likely formed south-southwest of Cape Farewell. The relatively fresh water replaced the locally formed convective water mass and continued to dominate the upper $1000 \mathrm{~m}$ of the water column until the following winter. In the winter of 20082009 the Irminger convective mixing strongly increased the salinity in the upper $800 \mathrm{~m}$, but left the intermediate salinity minimum intact. Although the water mass formed by convective mixing in the Irminger Sea differs from that formed in the Labrador Sea, the heat lost per unit area by convection is of the same order of magnitude in both basins.
\end{abstract}

(c) 2012 Elsevier Ltd. All rights reserved.

\section{Introduction}

Deep convective mixing provides a rare vertical connection in the meridional overturning circulation of the ocean. Surface cooling by the atmosphere transforms surface waters into highdensity deeper waters. In the North Atlantic Ocean, this process creates a link between the northward surface flow of warm waters in the Gulf Stream and North Atlantic Current system and the deep southward flow of cold water masses in the Deep Western Boundary Current and interior pathways (Bower et al., 2009). The extensive cooling of the sea surface needed for such a transformation is mainly provided by turbulent fluxes of sensible and latent heat due to a combination of strong winds and cold, dry air. However, because of the inherent stability of the ocean, strong cooling alone is not enough to induce convective mixing that reaches through the thermocline. The ocean must be preconditioned, in other words predisposed to overturn locally (Killworth, 1983; Marshall and Schott, 1999). This requires a weak overall stratification and preferably also a shallow thermocline. Areas which are both preconditioned and prone to strong

\footnotetext{
*Corresponding author. Tel.: +1 5082892631.

E-mail address: fdejong@whoi.edu (M.F. de Jong).

${ }^{1}$ Currently at Woods Hole Oceanographic Institution, Woods Hole, USA.
}

surface cooling are rare in the World's oceans. Well known sites of deep convective mixing are the Greenland Sea, the northwest Mediterranean Sea, the Labrador Sea and occasionally the Weddell Sea (Killworth, 1983). The circulation in these areas is generally cyclonic. This leads to isopycnal doming, partly outcropping in the center of the circulation, weakening the stratification and shoaling the thermocline.

In the North Atlantic and Nordic Seas the best known convection areas are the Greenland and Labrador Seas, although deep convective mixing (reaching beyond the seasonal thermocline) does not occur every year in these locations. In historic literature, the Irminger Sea was also named as an area of deep convection (Nansen, 1912; Sverdrup et al., 1942). This assumption was based on observations of well mixed profiles in the Irminger Sea. However, these historic bottle measurements had a coarse vertical resolution and limited accuracy. During the following decades, Ocean Weather Station Alpha was operated in the Irminger Sea until 1975. Unfortunately, the position of the Weather Station Alpha at $62^{\circ} \mathrm{N}$ and $33^{\circ} \mathrm{W}$ (Fig. 1) placed it outside of the area favorable for deep convection (Pickart et al., 2003). As a result, deep winter mixed layers were never observed at Ocean Weather Station Alpha, and the Irminger Sea lost attention as a location of deep convection. A similar observatory, Ocean Weather Station Bravo, was positioned in the Labrador Sea. Deep convection was observed at this station (Lazier, 1980), which turned the focus of 


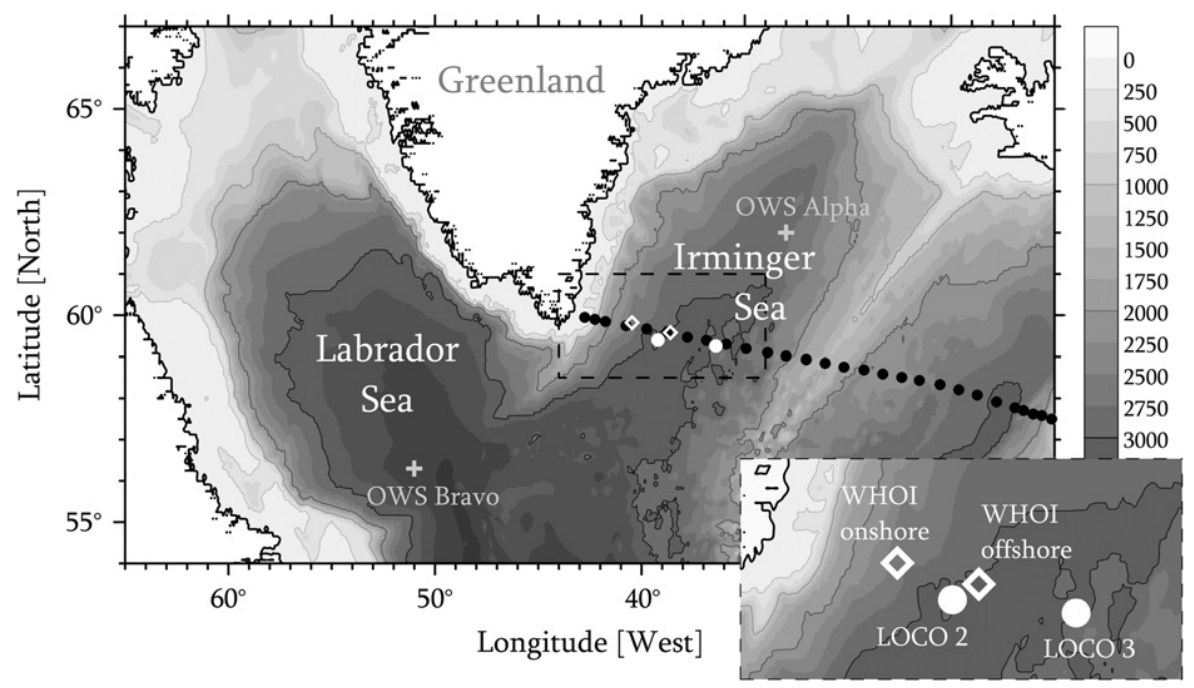

Fig. 1. Topography of the north-western North Atlantic Ocean. The depth of the topography (in m) is indicated by the grey colour scale. The locations of the two Ocean Weather Stations are indicated in the Figure. Examples of station positions along the AR7E section are illustrated with the black dots. The mooring positions are indicated with white circles for the NIOZ LOCO moorings and with white diamonds for the WHOI moorings. The relative locations of the 4 moorings are shown in more detail in the inset. The LOCO moorings are located approximately on the $3000 \mathrm{~m}$ isobath.

ocean convection studies to the Labrador Sea and the formation of Labrador Sea Water (LSW, Lazier et al., 2002). Tracer studies (Talley and McCartney, 1982; Yashayaev, 2007) tracked the advection of LSW to the nearby basins, including the Irminger Sea. The estimated travel time for LSW to the central Irminger Sea is 1 to 2 years (Yashayaev, 2007; Van Aken et al., 2011). Thus, the large resemblance between mid-level properties in the Irminger and Labrador Seas is thought to be caused mainly by advection of LSW.

The recent discussion about the notion of convection in the Irminger Sea was (re-)started by Pickart et al. (2003). They suggested that the volume of LSW observed in the Irminger basin may be formed locally by convection. Although there were no direct observations of deep convective mixing in the Irminger Sea at that time, their main arguments were compelling. First, a number of profiles from spring 1991 showed a nearly homogeneous water column with high oxygen saturation underneath a shallow $(\sim 200 \mathrm{~m})$ restratified layer, suggesting local or nearby convection had occurred shortly before. Second, the spatial distribution of hydrographic and chemical tracer properties observed in the Irminger Sea, with a maximum in the center of the basin, could not easily be explained by advection and diffusion alone because this predicts a maximum at the southeastern side of the basin. Third, Pickart et al. (2003) demonstrated the occurrence of a separate planetary potential vorticity (PV) minimum in the center of the Irminger Gyre (Lavender et al., 2000; Våge et al., 2011), indicative of the presence of a water mass homogenized by convective mixing. And finally, they proposed that the preconditioning of the Irminger Sea is similar to that of the Labrador Sea because of the large scale of the dominant weather systems. Local enhancement of air-sea heat fluxes by the Greenland Tip Jet (Doyle and Shapiro, 1999; Moore and Renfrew, 2005) was assumed to be strong enough to induce deep convective mixing (Pickart et al., 2003).

Following Pickart et al. (2003), several other studies investigated deep convective mixing in the Irminger Sea. Bacon et al. (2003) described convective mixing in the Irminger Sea based on observations with profiling floats, which showed mixed layers down to 700 and $1000 \mathrm{~m}$ in the Irminger Sea in 1997. Centurioni and Gould (2004) derived a typical mixed layer depth of about $400 \mathrm{~m}$ for the period 1997 to 2003 based on floats and onedimensional models. It is unclear whether the mixed layers in the Irminger Sea (such as observed in 1997) were able to form LSW locally (as suggested by Falina et al. (2007) and Bacon et al. (2003)) or not (Bersch et al., 2007). This ambiguity is largely due to the fact that most observation from both the Labrador Sea and Irminger Sea (e.g., CTD surveys) are made in summer. In order to obtain more direct observations of convection, moorings fitted with an autonomous CTD (Conductivity, Temperature, Depth) profiler (Doherty et al., 1999) were subsequently deployed in the Irminger Sea by the Woods Hole Oceanographic Institution (WHOI). These moorings were deployed between August 2001 and August 2004 at two locations, one over the continental slope near $40^{\circ} \mathrm{W}$ and the other near the $3000 \mathrm{~m}$ isobath near $39^{\circ} \mathrm{W}$ (Våge et al., 2008 and Fig. 1 here). However, all of the winters considered above were relatively weak compared to those of the early 1990s. Mixed layers observed by the WHOI offshore moorings only rarely exceeded $400 \mathrm{~m}$ (Våge et al., 2008), similar to the mixed layers observed by the floats. Mixed layers were much shallower at the location of the onshore mooring. Likely because it was located further from the weakly stratified centre of the Irminger Gyre and closer to the buoyant East Greenland Current.

In September 2003 two new moorings were deployed in the Irminger Sea by the NIOZ Royal Netherlands Institute for Sea Research. These were located at $39^{\circ} \mathrm{W}$ and $36^{\circ} \mathrm{W}$ near the $3000 \mathrm{~m}$ isobath in the central Irminger Sea (Fig. 1). The eastern mooring was operational until September 2008 while the western mooring is still in operation. Similar to the WHOI moorings, these moorings were fitted with an autonomous CTD profiler, travelling up and down the mooring cable while recording hydrographic profiles. The long duration of these deployments allowed the moorings to sample a larger range of winters, including the weaker winters of the early 2000s as well as the cold winter of 2007-2008 (Våge et al., 2009; Yashayaev and Loder, 2009). That winter forced the return of deep convection (down to $\sim 1600 \mathrm{~m}$ ) in the Labrador Sea and the formation of a new class of LSW (Yashayaev and Loder, 2009). The observations from the NIOZ moorings show that deep convective mixing, down to about $1000 \mathrm{~m}$ depth, also occurred in the central Irminger Sea during this winter. This is in agreement with Argo float data presented by Våge et al. (2009). Furthermore, mixing down to similar depths was observed in the subsequent winter of 2008-2009, which was not as strong in terms of surface heat fluxes. These observations are the first direct evidence of deep convective mixing, reaching down to the level of the LSW, in the Irminger Sea. 
In this paper we present the data of the two NIOZ profiling moorings covering the winters between fall 2003 and summer 2010. Time series from the WHOI offshore mooring are also included and serve as an extension of the high resolution data set back to the winter of 2002-2003. (These WHOI data have been presented before by Våge et al., 2008). The earlier winter, of 2001-2002, was not well observed by the WHOI offshore mooring due to problems with the CTD profiler and could not be added to this time series. Combining the WHOI and NIOZ data sets enables us to characterize the typical mixed layer depth and mixed layer evolution in eight successive winters observed in the central Irminger Sea between 2002 and 2010 as well as to describe some important inter-annual and lateral variability. Argo float data are used to put the mooring observations in a broader perspective. The paper is structured as follows. The mooring data are introduced in Section 2, as well as float data, sea surface height and heat flux data which are used further in the paper. Section 3 contains a short description of the hydrography of the Irminger Sea, with emphasis on the local stratification, preconditioning and surface forcing. Section 4 focuses on the mooring observations, beginning with a description of the mixed layers observed between 2003 and 2010. This section also includes an investigation into the hydrographic properties of the water formed in the mixed layers and the restratification of the water column after convection. The discussion about the formation of LSW in the Irminger Sea is revisited in Section 5. In this section the observations of mixed layers in the Irminger Sea will be compared to those observed by floats in the Labrador Sea and south of Cape Farewell in the same winter. Section 6 contains a concluding summary.

\section{Data}

Our data set contains 7 years from the western NIOZ mooring (fall 2003 to fall 2010) and 5 years from the eastern NIOZ mooring (fall 2003 to fall 2008), both are located in the central Irminger Sea. Two winters, between fall 2002 and spring 2004, observed by the WHOI offshore mooring are also included. All information of these mooring deployments is contained in Table 1 . The NIOZ moorings are part of the Long-term Ocean Climate Observations (LOCO) program. The western mooring, LOCO 2 , is located near $39^{\circ} 30^{\prime} \mathrm{W}$ and $59^{\circ} 12^{\prime} \mathrm{N}$. Originally, during the first deployment, the LOCO 2 mooring was placed slightly further to the north-east (at $39^{\circ} 00^{\prime} \mathrm{W}$ and $59^{\circ} 26^{\prime} \mathrm{N}$ ). The mooring designated LOCO 3 was located further east at $36^{\circ} 24^{\prime} \mathrm{W}$ and $59^{\circ} 15^{\prime} \mathrm{N}$. The horizontal distance between the

Table 1

Deployment information of the WHOI mooring and the two NIOZ LOCO moorings. The date of the first profile after deployment, the date of the last profile before recovery, total number of profiles and the amount of data recovered.

\begin{tabular}{lllll}
\hline Designation & First profile & Last profile & No. of profiles & $\begin{array}{l}\text { Data } \\
\text { recovered }\end{array}$ \\
\hline WHOI 0203 & 13 Aug 2002 & 2 Jun 2003 & 582 & $81 \%$ \\
WHOI 0304 & 3 Aug 2003 & 25 Mar 2004 & 471 & $78 \%$ \\
LOCO 2-1 & 3 Sep 2003 & 1 Oct 2004 & 394 & $89 \%$ \\
LOCO 2-2 & 5 Oct 2004 & 15 Sep 2005 & 345 & $88 \%$ \\
LOCO 2-3 & 16 Sep 2005 & 24 Sep 2006 & 342 & $81 \%$ \\
LOCO 2-4 & 28 Sep 2006 & 14 Apr 2007 & 299 & $53 \%$ \\
LOCO 2-5 & 12 Sep 2007 & 10 Sep 2008 & 364 & $83 \%$ \\
LOCO 2-6 & 15 Sep 2008 & 2 Oct 2009 & 382 & $95 \%$ \\
LOCO 2-7 & 3 Oct 2009 & 18 Jul 2010 & 289 & $62 \%$ \\
LOCO 3-1 & 29 Aug 2003 & 5 Oct 2004 & 403 & $95 \%$ \\
LOCO 3-2 & 6 Oct 2004 & 13 Sep 2005 & 343 & $44 \%$ \\
LOCO 3-3 & 14 Sep 2005 & 29 Aug 2006 & 349 & $98 \%$ \\
LOCO 3-4 & 2 Sep 2006 & 9 Sep 2007 & 372 & $21 \%$ \\
LOCO 3-5 & 11 Sep 2007 & 14 Sep 2008 & 369 & $98 \%$ \\
\hline
\end{tabular}

two LOCO moorings is about $180 \mathrm{~km}$ and both are located near the AR7E hydrographic section (Fig. 1), which is one of the World Ocean Circulation Experiment repeat survey lines (Bersch, 1995). The location of the moorings with respect to the hydrography observed along the AR7E section is illustrated in Fig. 2.
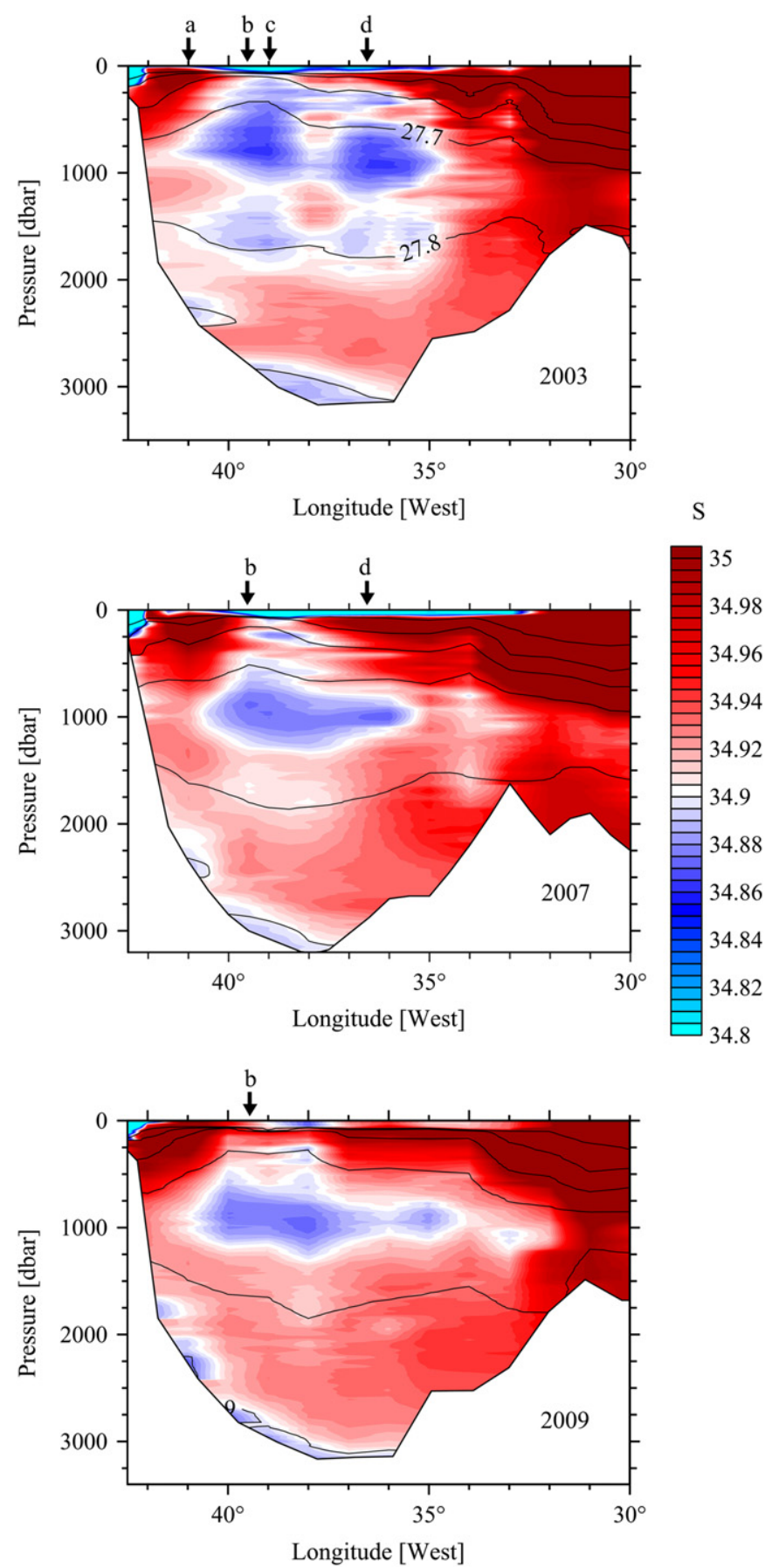

Fig. 2. Hydrography along the AR7E section through the Irminger Sea surveyed by the RV Pelagia in September 2003 (top panel), September 2007 (middle panel) and October 2009 (lower panel). Shown in colour are the salinity distributions. Isopycnals $\left(27.4 \leq \sigma_{0} \leq 27.9 \mathrm{~kg} \mathrm{~m}^{-3}\right)$ are drawn with black lines at $0.01 \mathrm{~kg} \mathrm{~m}^{-3}$ intervals. The arrows at the top of the panels indicate the mooring positions with respect to the hydrography. From west to east; (a) WHOI onshore mooring, (b) NIOZ LOCO 2 mooring, (c) WHOI offshore mooring and (d) NIOZ LOCO 3 moorings. The LOCO 2 and the WHOI offshore moorings are located in the most weakly stratified part of the Irminger Sea. In the centre of the Irminger Sea the upper and lower Labrador Sea Water cores are also found $(S<34.90$, blue colours), a saline eddy is found in the centre of the basin in the 2003 survey. 
On all of the moorings, vertical profiles were recorded by McLane Moored Profilers (MMPs, Doherty et al., 1999). The MMP is an autonomous CTD (Conductivity, Temperature, Depth) profiler which measures conductivity, temperature and pressure along the cable between pre-programmed depths. Both the WHOI and the LOCO MMPs were equipped with an CTD sensor from Falmouth Scientific Inc., which has a specified accuracy of $0.005{ }^{\circ} \mathrm{C}$ in temperature, $0.0005 \mathrm{~S} \mathrm{~m}^{-1}$ in conductivity and $0.05 \%$ of the full scale pressure, sampling at a frequency of $1.83 \mathrm{~Hz}$, resulting in at least 8 samples per dbar. For the LOCO moorings, the MMP was set to traverse the cable once per day between $\sim 150$ and $\sim 2400$ dbar depth. Thus, top-to-bottom and bottomto-top profiles alternate in the resulting time series. The data retrieval was generally good (full 150 to 2400 dbar profiles) during the first few months of the deployments and gradually deteriorated as time progressed, likely due to lowered battery capacity and bio-fouling of the cable. Most deployments achieved a data recovery of over $80 \%$ (Table 1 ), but on three occasions the data recovery was significantly lower. Only one of these, the fourth deployment of LOCO 2, was due to a technical failure of the device. In particular, chafing of the insulation of an electric cable led to a short-circuit 3 months before the end of the deployment. On two other occasions (the second and fourth deployments of LOCO 3) the MMP was trapped on the cable by an unknown obstacle for long periods of time, and therefore could not complete its profiles. The WHOI MMPs were programmed to traverse the cable twice per day between $\sim 65$ and $\sim 1800$ dbar. The first mooring deployment (2001-2002) failed shortly after deployment and is therefore not included in this study. The second and third deployments, WHOI 0203 and WHOI 0304 (Table 1 here and Våge et al., 2008), recorded profiles successfully during the full deployment period although the MMP tended to drift towards its neutral density position between profiles, effectively shortening the profiles. The data recovery achieved by the WHOI offshore moorings is $81 \%$ for the 2002-2003 deployment and $78 \%$ for the $2003-2004$ deployment.

The MMP data from the NIOZ and WHOI moorings were processed and calibrated at their respective institutes of origin. Processing of the WHOI data is described in Vagge et al. (2008). Basic processing at both institutes included automatically despiking followed by a manual check for remaining outliers. Potential temperature, salinity and potential density were derived from the edited data sets. Subsequently, data were averaged in $1 \mathrm{dbar}$ (NIOZ) or 2 dbar (WHOI) bins, which strongly reduced small scale noise. The MMP data were calibrated using shipboard CTD profiles recorded at the time of deployment and recovery at the mooring location. The biases between the MMP CTD and the ship's CTD were determined in the deeper parts of the water column where the day-to-day variability is relatively low. Corrections were made for both temperature and salinity profiles. Thereafter the potential density was recalculated and checked for consistency with the both the shipboard CTD and between subsequent MMP deployments. The applied corrections in temperature and salinity were constant offsets, rather than depth dependent, and effects of this correction on the determined mixed layers depth and potential vorticity are negligible.

Mixed layer depths in the MMP time series were determined by visual inspection of all profiles. For this determination the salinity, potential temperature and potential density profiles were compared. Since the upper $150 \mathrm{~m}(60 \mathrm{~m})$ of the water column are not covered by the MMPs in the LOCO (WHOI) moorings, shallow mixed layers are not recorded. Mixed layers that appear in the MMP profiles (and thus exceed 60 or $150 \mathrm{~m}$ ) are assumed to be caused by convective mixing. The agreement between the timing of the surface cooling and the appearance of mixed layers supports this assumption. Also, no mixed layers are observed (beneath $150 \mathrm{~m}$ ) during summer despite occasionally strong winds. Mixed layers are generally observed in winter and early spring profiles. The profiles of all three variables were required to show a well-mixed layer in order to assign a mixed layer depth to the profile. The depth of the mixed layer was chosen to be the bottom of the well mixed part of the profile, just above the sharp gradient between the mixed layer and the "undisturbed" profile. This discontinuity is seen in the salinity and potential temperature profiles throughout winter. In the potential density profiles this step gradually diminishes during winter until it nearly disappears at the end of winter as the mixed layers reach their maximum depth and density. In the absence of a density gradient, the gradients found in the temperature and salinity profiles were leading in the determination of the mixed layer depth. For profiles containing several stacked mixed layers (e.g., Pickart et al., 2002), the bottom of each mixed layer was recorded. Occasionally tilted mixed layers were observed. These mixed layers are homogeneous except for a small background gradient, which may be the result of rotational control (Straneo et al., 2002) or advection of a convective cell past the mooring. Tilted mixed profiles were only recorded as mixed layers if all three variables were well mixed and the deviation from vertical in the profiles was small. In order to check the subjectively determined mixed layer depths, the standard deviation of the three variables in the mixed layer were evaluated. The standard deviation for salinity was required to be smaller than 0.005 , while the potential temperature and density standard deviations needed to remain below $0.05{ }^{\circ} \mathrm{C}$ and $0.05 \mathrm{~kg} /$ $\mathrm{m}^{3}$, respectively. Mixed layers which exceeded these values were discarded. The remaining mixed layers provide a good indication of the depths reached by convective mixing at the mooring location.

A more objective measure of the mixed layer depth was derived by calculating the planetary potential vorticity (PV) of the profiles. More importantly, the PV allows us to follow the mixed water mass as it is subducted by restratification. To suppress small scale noise, the profiles were first smoothed using a running mean with a window of 50 dbar. The planetary potential vorticity was than calculated over 25 dbar intervals as such:

$P V=-f / \rho \cdot \partial \rho /\left.\partial z\right|_{a d}$

where $f$ is the coriolis parameter, $\rho$ is the density, $\partial \rho /\left.\partial z\right|_{a d}$ the adiabatic vertical density gradient and the vertical coordinate $z$ is directed upward.

The hydrographic properties of the mixed layers were also determined. For single mixed layers this is the simple average of salinity, potential temperature and potential density between the top of the profile and the bottom of the mixed layer. For multiple stacked mixed layers the properties of the uppermost mixed layer is calculated similarly. For subsequent, deeper mixed layers the top is assumed to be 20 dbar below the depth indicated as the bottom of the overlaying mixed layer. The 20 dbar gap assures that the gradient or step between the two mixed layers is not incorporated into the average. For the gradient in the hydrographic properties between the lowest mixed layer and the undisturbed profile a wider, $50 \mathrm{dbar}$, criterion was used.

Atmospheric data were used to study the surface forcing responsible for driving the convective mixing and its inter-annual variability. Surface heat fluxes were downloaded from the Objectively Analyzed air-sea Fluxes (OAflux) project at http://oaflux. whoi.edu/ (Yu et al., 2004). The OAflux uses the NCEP reanalysis as well as ECMWF operational analysis and thereby tries to avoid the biases of both. The resulting OAflux data set has a $1^{\circ}$ by $1^{\circ}$ spatial resolution. The daily turbulent (sensible and latent) heat fluxes were downloaded for the period from January 2002 to 
July 2010. Daily radiative heat fluxes (short and long wave) and net heat fluxes were available up to December 2007. Time series of heat fluxes were averaged for the central Irminger Sea, between $42^{\circ}$ to $34^{\circ} \mathrm{W}$ and $57^{\circ}$ to $62^{\circ} \mathrm{N}$. At this location the inter-annual variability of the shortwave and longwave heat fluxes is relatively small (De Jong, 2010). Furthermore, during winter the radiative heat fluxes are an order of magnitude smaller than the turbulent heat fluxes. Since we are interested in winter cooling, the turbulent fluxes, which were available until July 2010 , are most important. The time series of radiative heat fluxes was extended from December 2007 to July 2010 by substituting the missing radiation data with the mean annual cycle of radiative heat fluxes determined from the 2002-2007 data. The differences between the individual annual means of the years between 2002 and 2007 and the mean of the 2002 to 2007 mean annual cycle range from -1.1 to $0.9 \mathrm{~W} \mathrm{~m}^{-2}$, which is not significant. The substitution does lead to some loss of synoptic variability especially in summer, but this is not our season of interest. Therefore, we assume that the heat fluxes derived for the winters of 2007-2008, 2008-2009 and 2009-2010 from the extended time series are a good approximation for the values of OAflux that will become available in the future.

Sea surface height (SSH) data (the Ssalto/Duacs Gridded Absolute Dynamic Topography), obtained from AVISO at http:// www.aviso.oceanobs.com/, are used to study the circulation of the Irminger Gyre. Weekly gridded sea surface height fields were downloaded for the period 2002 to 2009. A time series for the centre of the Irminger Gyre was composed by averaging over a box between $42^{\circ}$ and $36^{\circ} \mathrm{N}$ and $58^{\circ}$ to $61^{\circ} \mathrm{W}$. This box includes the low pressure of the gyre as well as the NIOZ and WHOI moorings
(Fig. 3). The time series of the area average of the box show a high correlation $(R=0.88)$ with the SSH minimum of the gyre, but is slightly smoother.

Finally, Argo float data are used to further investigate the winters between January 2007 and December 2010. For the first winter, 2007-2008, this data set is similar to the one used by Våge et al. (2009). For this study the data set has been extended until December 2010. The Argo data set was obtained from www. usgodae.org. It includes hydrographic profiles and GPS positions for floats which circulated in the Irminger and Labrador Seas, defined here as a box from $51^{\circ}$ to $67^{\circ} \mathrm{N}$ and $60^{\circ}$ to $30^{\circ} \mathrm{W}$. This set contains 5579 profiles from 108 individual floats. Argo floats drift at a parking depth of $1 \mathrm{~km}$ and have a 10 day cycle. This cycle includes one hydrographic profile between $2 \mathrm{~km}$ depth and the sea surface, which is transmitted to shore via satellite along with its geographic location. Thus the floats provide both vertical profiles and information on the mid-depth circulation. Mixed layer depths of surface-connected mixed layers were determined for the quality checked float profiles using the algorithms described by Holte and Talley (2009). This algorithm employs several methods to determine the mixed layer depths, a threshold method, a gradient method and a straight line fit method. The algorithm then chooses the result that is most appropriate for the particular profile. Not all floats were equipped with a conductivity sensor, therefore we used mainly the mixed layer depth results based on the temperature profiles. For the winter of 2007-2008 these results are nearly identical to that of Våge et al. (2009), the two subsequent winters have not been analysed before to our knowledge. Profiles of PV were determined for float profiles that did include salinity, and thus also density, observations.
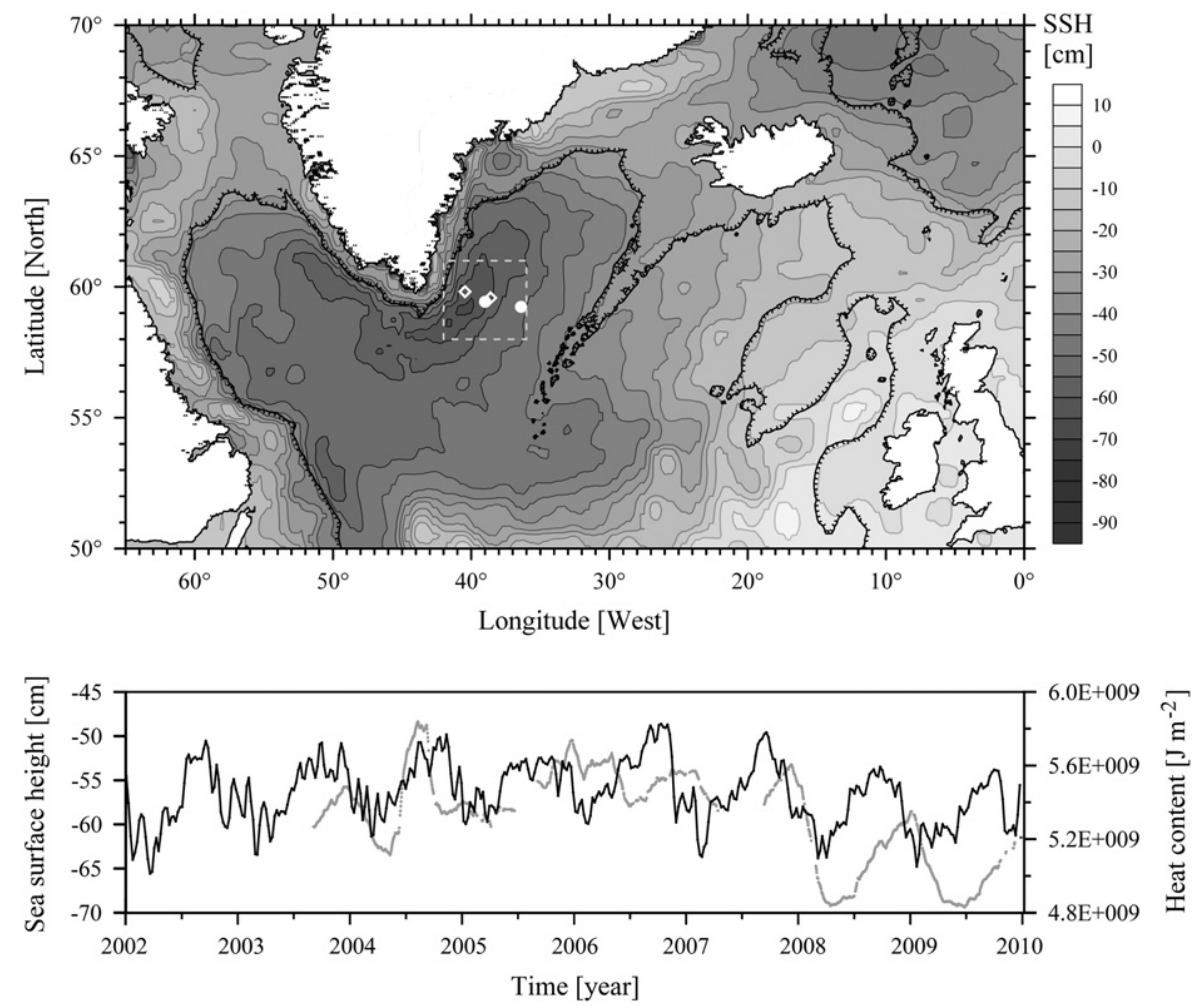

Fig. 3. The top panel shows the 2002-2009 mean sea surface height field for the subpolar North Atlantic, with isolines drawn every $5 \mathrm{~cm}$. The $1500 \mathrm{~m}$ isobath of the topography is indicated by the hashed line. Also indicated are the positions of the LOCO (white dots) and WHOI (white diamonds) moorings in the central Irminger Sea. The bottom panel illustrates the evolution of the AVISO sea surface height (in black) and heat content (in grey) in the central Irminger Sea. AVISO weekly fields (Ssalto/Duacs Gridded Absolute Dynamic Topography) were averaged over a box $\left(42^{\circ} \mathrm{W}\right.$ to $36^{\circ} \mathrm{W}$ and $58^{\circ} \mathrm{N}$ to $61^{\circ} \mathrm{N}$, indicated by the dashed line in the upper panel) that includes the centre of the low pressure system associated with the Irminger Gyre. The heat content was derived from the LOCO 2 mooring data for the layer that has the strongest seasonal signal (200 to $500 \mathrm{~m})$. 


\section{Regional hydrography, preconditioning and forcing between 2002 and 2010}

Before presenting the mixed layer observations, we begin by describing the regional hydrography and the main factors that influence the convective mixing, both seasonally and interannually; namely the water column preconditioning and the air-sea buoyancy forcing. To illustrate the hydrography of the Irminger Sea and its inter-annual variability we present the salinity and density distributions along the western part of the AR7E section in Fig. 2. Shown are three occupations of the AR7E section. The first survey was performed in September 2003, at the start of the LOCO deployments. The second survey was performed in September 2007, before the strong winter of 2007-2008. The third survey is that of October 2009, the last survey of the AR7E section before the end of the LOCO time series presented here. The hydrographic structure of the water column largely determines the preconditioning prior to the onset of convection. Both on the eastern and western side of the basin the stratification is unfavorable for convection due to the stably stratified boundary currents. On the eastern side the stable waters are found in the warm Irminger Current, while on the western side the boundary current consists of the East Greenland Current (EGC) in the upper layers and the extension of the Irminger Current underneath. These two currents together were referred to as the Western Boundary Current in Våge et al. (2011). The EGC transports relatively cold and fresh water south along the east Greenland shelf, around Cape Farewell and northward along the west Greenland shelf. There it is called the West Greenland Current (WGC). Downstream of Cape Farewell the Greenland continental shelf narrows and the WGC becomes unstable. This results in the shedding of eddies by the WGC to the interior of the Labrador Sea (Eden and Böning, 2002), thus providing a source of freshwater to the centre of the basin (Hátún et al., 2007). No such instability is seen in the EGC on the east Greenland shelf, along the boundary of the Irminger Sea. Only at Cape Farewell, does the EGC occasionally retroflect (Holliday et al., 2007), due to a topographic feature called Eirik Ridge. This retroflection seems to be one of the few sources of freshwater of the Irminger Sea, in addition to precipitation. A shallow layer of relatively fresh water, 30 to $100 \mathrm{~m}$ deep, can occasionally be observed along the AR7E sections in the central Irminger Sea (Fig. 2). Beneath this relatively fresh layer a salinity maximum can be found. This salinity maximum corresponds to the Subpolar Mode Water (SPMW, McCartney and Talley, 1982; Brambilla and Talley, 2008). The warmest and most saline SPMW is found in the Irminger Current, on the eastern side of the basin (Fig. 2). Part of the SPMW recirculates in the Irminger Gyre, defined by Lavender et al. (2000) and Våge et al. (2011) as the narrow area with low geostrophic pressure in the western part of the Irminger Basin (Fig. 3). There it is modified by surface cooling and mixing with the fresher surface waters. The remainder of SPMW continues to the Labrador Sea in the Western Boundary Current. Due to progressive modification the SPMW in the Labrador Sea is much less saline and stably stratified than the SPMW in the central Irminger Sea (De Jong, 2010). Together with the surface freshwater flux the SPMW largely determines the salinity of convective products in both basins.

The intermediate part of the Irminger Sea water column resembles its Labrador Sea counterpart much more closely. This is partly because Labrador Sea Water, formed convectively in the Labrador Sea, is advected into the central Irminger Sea (Talley and McCartney, 1982; Lavender et al., 2000). The time lag between the formation of LSW and the arrival of LSW in the Irminger Sea is approximately 1 to 2 years (Yashayaev, 2007; Van Aken et al., 2011). Two separate classes of LSW were present in the central
Irminger Sea in 2003, at the time of the first LOCO mooring deployment. These two classes are visible in the top panel of Fig. 2, where they can be recognized by their salinity minima. The upper volume of LSW is the class formed in the winter of 2000 , called upper LSW (Rhein et al., 2007) or LSW 2000 (Yashayaev, 2007). The lower volume of LSW is the remnant of the large class of LSW formed by convection in the early 1990s, called classical/ lower LSW or $\mathrm{LSW}_{94}$ for its peak volume reached in 1994. The $\mathrm{LSW}_{94}$ had already decayed substantially since its maximum hydrographic expression in the Irminger Sea in 1996-1997 (Yashayaev, 2007; Sarafanov et al., 2007) and continued to decay after 2003 (Van Aken et al., 2011). Its salinity minimum has nearly completely disappeared in the survey of 2007 (Fig. 2). The 2003 survey (Fig. 2) shows relatively young LSW $_{2000}$ in the upper part of the central Irminger Sea. This LSW core decayed substantially during the following years (Van Aken et al., 2011). In 2007 the LSW core is seen to be more saline and reduced in volume compared to 2003. These changes are part of large scale increases in salinity and temperature seen across the Subpolar Gyre (Sarafanov et al., 2007), thought to be caused by changes in the Subpolar Gyre itself (Hátún et al., 2005). This change is illustrated by the less pronounced doming of the isopycnals in 2007 (Fig. 2). In the survey of 2009 the gyre appears to be stronger again, with the doming of the isopycnals similar to 2003. The salinity minimum in the survey of 2009 is formed by convection in the winter of 2007-2008 (Våge et al., 2009; Yashayaev and Loder, 2009) and was possibly modified by convection in the winter of 2008-2009 as we will show here. The doming isopycnals of the cyclonic gyre and the presence of the weakly stratified convective waters at intermediate levels in the Irminger Sea significantly lowers the local convective resistance for deep mixed layers. The isopycnal doming is enhanced by a strengthening in the cyclonic surface currents during winter (Flatau et al., 2003), further weakening the stratification. The velocity structure of the Irminger Gyre and its inter-annual variability between 1991 and 2007 has been described extensively by Våge et al. (2011). Together, the weakly stratified LSW in the interior and the cyclonic Irminger Gyre seem to satisfy the preconditioning conditions required for convection as discussed by Marshall and Schott (1999).

The circulation was sampled at the NIOZ mooring locations with Acoustic Doppler Current Profilers (ADCPs, not shown) fitted in the top buoys of the moorings. The current direction, sampled between 200 and $500 \mathrm{~m}$ depth, at the western mooring, LOCO 2, is predominantly directed to the north-east. This indicates that the mooring is located to the east of the gyre centre. This agrees with the findings of Lavender et al. (2000) and Våge et al. (2011), which show a narrow centre of the Irminger Gyre on the far western side of the basin (Fig. 3). The time series from the LOCO 3 mooring, located further east and closer to the Irminger Current, mainly show the presence of eddies, with very little net flow. The ADCP data from LOCO 2 show a seasonal cycle, with an increase in the north-eastward directed near-surface current during each winter between 2003 and 2008. This confirms Flatau et al. (2003)'s observations of a stronger wintertime circulation and follows the seasonal cycle in the SSH in the centre of the Irminger Gyre (bottom panel of Fig. 3). However, in the autumn of 2008 the current showed very strong variability (with a strong tidal signature), leading to a reversal of the mean flow. While this reversal of the mean flow is remarkable, we cannot find a significant change in the position of the gyre in the SSH data during this period. The AVISO sea surface height data do show that the centre of the Irminger Gyre was quite low during the autumn of 2008 compared to previous years. Low SSH is strongly related to low heat content of the water column (Volkov and van Aken, 2003) and thus to stronger preconditioning. This is confirmed by the time series of heat content of the upper layer 
displayed in Fig. 3. Thus, it appears that the centre of the Irminger Sea was indeed more strongly preconditioned in the autumn of 2008 than in previous years.

Surface cooling is generally believed to have a stronger effect on the inter-annual variability in convective mixing, more so than inter-annual variability in preconditioning. The heat fluxes over the central Irminger Sea between 1 January 2002 and 31 July 2010 are shown in Fig. 4. These heat fluxes are significantly correlated $(R=0.6)$ to the heat fluxes derived similarly from the OAflux data set for the Labrador Sea. The heat fluxes over the Irminger Sea are on average $\sim 80 \%$ of those observed over the Labrador Sea. A similar ratio of Irminger Sea to Labrador Sea heat fluxes was found using the NCEP reanalysis (De Jong, 2010). The OAflux Irminger Sea mean net heat flux, and its standard deviation, over the general cooling period or extended winter (ONDJFM) illustrates the relative strength of these 8 consecutive winters (red bars in the lower panel of Fig. 4). The first five winters appear to be quite moderate, although shortduration, strong cooling events are observed in the winter of 20042005. Overall, mixed layer conditions during these five winters were similar to that of the winter of 2002-2003, during which Våge et al. (2008) observed general mixed layer depths of about $400 \mathrm{~m}$ in the central Irminger Sea. During the winter of 2007-2008, on the other hand, the maximum heat fluxes, as well as the overall winter mean heat loss, was much higher. Conditions over the Irminger Sea were similar to the conditions over the Labrador Sea, where deep $(\sim 1600 \mathrm{~m})$ convection returned in the same winter (Våge et al., 2009; Yashayaev and Loder, 2009). We will show that the depths reached by convective mixing in the Irminger Sea were also positively affected in the winter of 2007-2008, which confirms the findings of Våge et al. (2009). The last two winters, 2008-2009 and 2009-2010, were less cold and more similar to the winters prior to 2007.

\section{Observed mixed layers in the Irminger Sea}

Both the time series of the planetary potential vorticity and the manually determined mixed layer depths are shown in Fig. 5 . The upper $150 \mathrm{~m}(60 \mathrm{~m})$ of the water column were not observed by the LOCO (WHOI) moorings. In order to focus on the mixed layers, the observations below 1500 are not included in this figure.

Before going into more detail, we point out the general structure visible in Fig. 5. In the stratification one can recognize the hydrographic structure of the water column as discussed in Section 3. Because the near-surface layer is not observed by the moorings the strong stratification in the fresh surface layer is not visible here. Underneath the uppermost layer, the water column in the central Irminger Sea consists of stably stratified SPMW (green-blue colours). At depths between 750 and $1250 \mathrm{~m}$ the intermediate PV minimum of the $\mathrm{LSW}_{2000}$ is visible (orange-red colours). The decaying $\mathrm{LSW}_{94}$ is observed at deeper levels at the beginning of the mooring deployment, but its signature has completely disappeared in recent years (Fig. 2). Since our focus here lies on the seasonal variability of the mixed layers, the observations below $1500 \mathrm{~m}$ are not shown in Fig. 5. Some horizontal gradients can also be discerned between the three moorings. The LOCO 2 and WHOI offshore mooring are located near the centre of the Irminger Gyre. Here the isopycnal doming is strongest, which results in a shallower layer of SPMW. This stably stratified layer is $\sim 500 \mathrm{~m}$ in the centre of the basin and deepens towards the Irminger Current, it is observed to be about $\sim 750 \mathrm{~m}$ deep at LOCO 3 mooring. The largest remaining (homogeneous) volume of $\mathrm{LSW}_{2000}$ appears to be present at the LOCO 2 mooring site. This reflects the circulation at deeper levels. The LSW first enters the Irminger Sea on the eastern side and then continues cyclonically around the basin (Våge et al., 2011). As the LSW
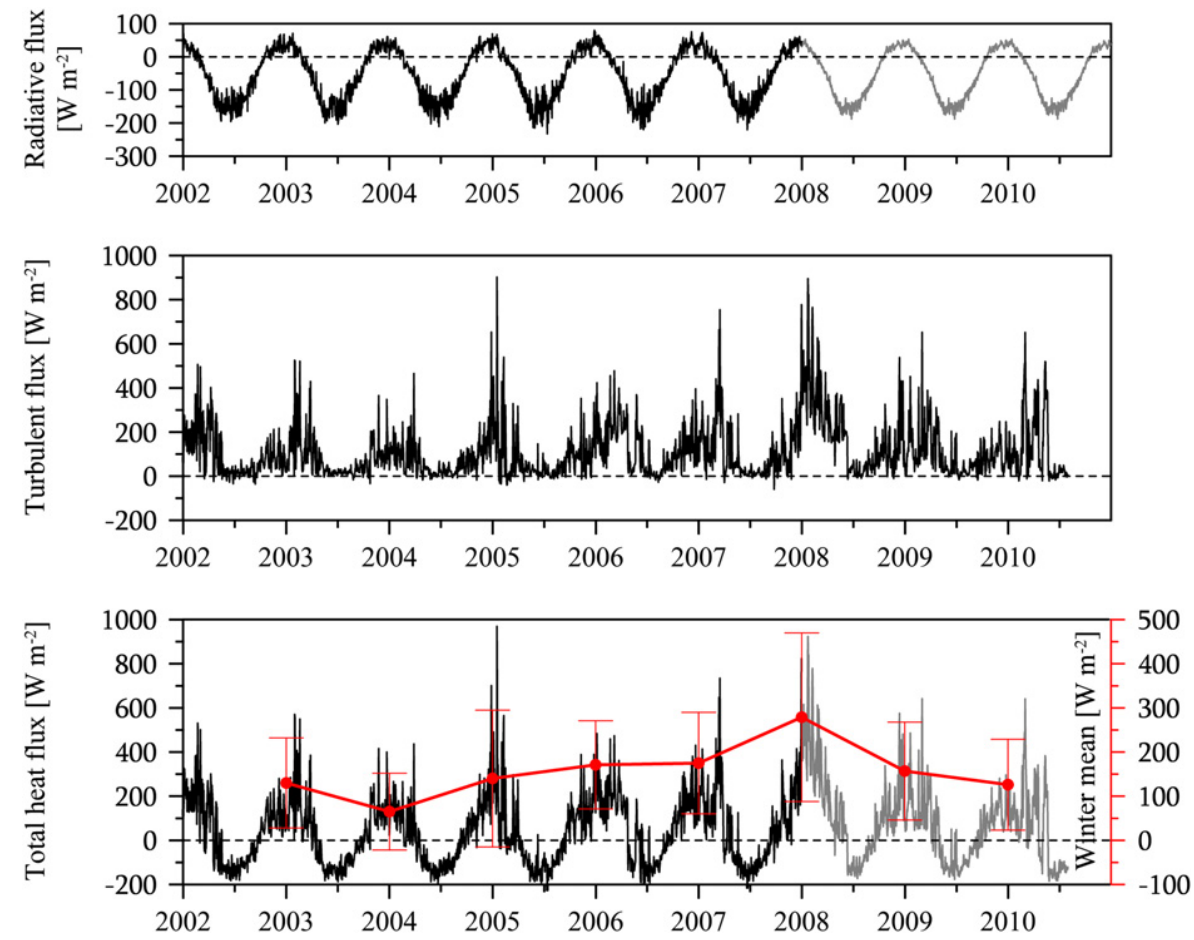

Fig. 4. Radiative, turbulent and total heat upward fluxes over the central Irminger Sea obtained from OAflux. The radiative (shortwave+longwave) heat flux is shown in the top panel. The OAflux time series from 2002 to 2007 is drawn in black. This time series is extended with the annual mean radiative heat flux curve for the years 2008 to 2010 (drawn in grey in the same panel). The middle panel shows the turbulent (sensible+latent) heat flux flux, which is available from OAflux for the period 2002 to July 2010. The bottom panel shows the total net (radiative+turbulent) heat flux. This time series is composed of the original radiative heat flux for the period 2002 to 2007 (black line), and the extended radiative heat flux for 2008 to July 2010 (grey line). The mean winter (1 October to 31 March) heat flux and its standard deviation are drawn in red in the lower panel. 


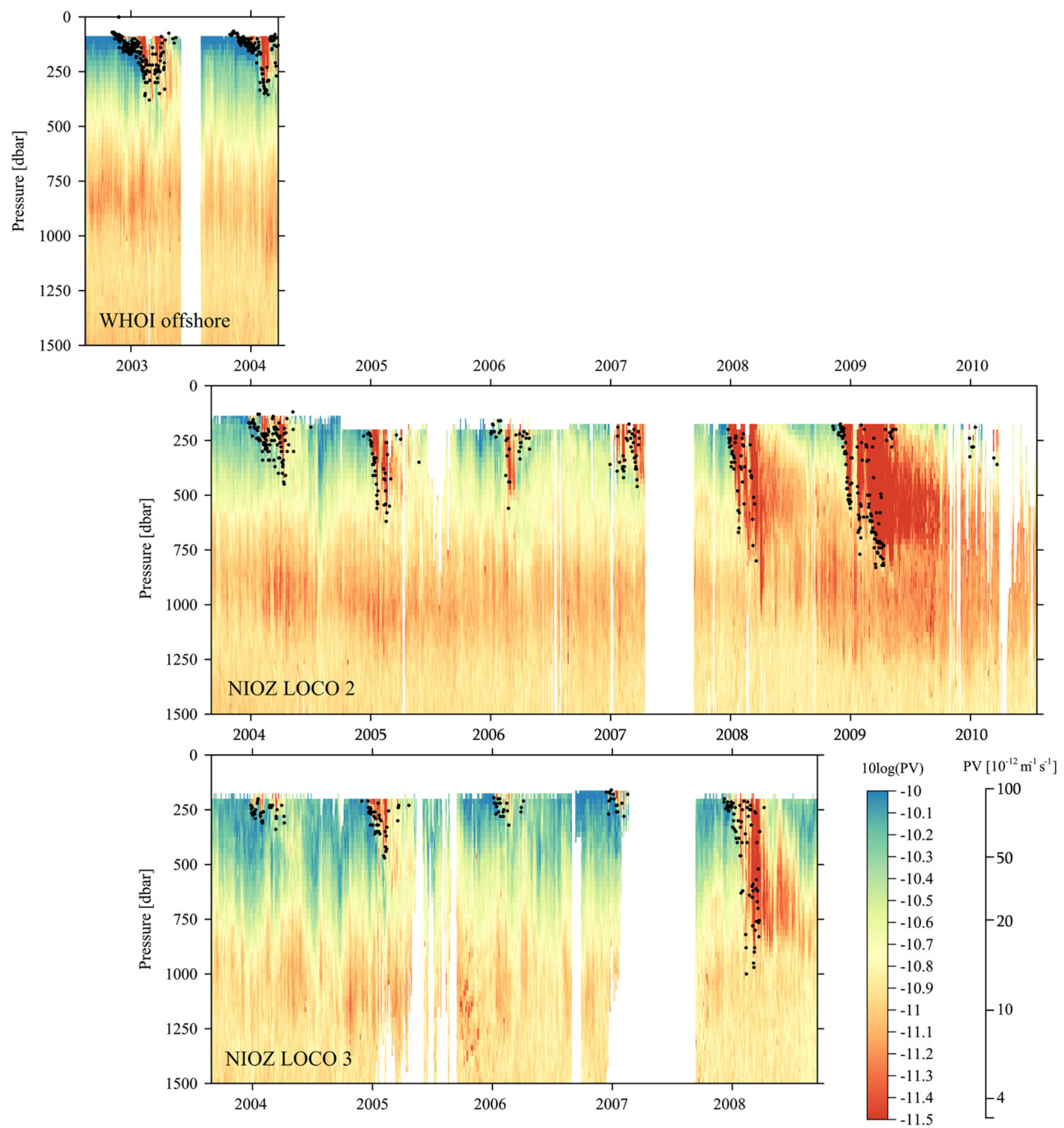

Fig. 5. Potential Vorticity and observed mixed layer depths of the three moorings deployments. The PV is plotted as a log scale to bring out the differences more clearly. Low PV values $\left(<410^{-12} \mathrm{~m}^{-1} \mathrm{~s}^{-1}\right)$ come out as red colours. The bottom of the deepest mixed layer observed in the profiles is marked by the black dots. The uppermost panel illustrates winter mixing during the WHOI offshore mooring deployment. The middle (lower) panel contains the PV series from the LOCO 2 ( 3 ) mooring. The middle and lower panel clearly show the enhanced mixing in the winters of 2007-2008 and 2008-2009 and the changes in the near-surface and intermediate PV minimum.

decays, the western signals, which arrived somewhat later, endures longer.

On top of this general structure one clearly sees the seasonal cycle in the stratification of the upper 500 to $1000 \mathrm{~m}$ as well as a strikingly large inter-annual variability. This seasonal cycle is connected to local winter convective mixing, which appears to have been substantial in the winters of 2007-2008 and 20082009. Because of this large inter-annual variability we have split the characterization of convective mixing in the Irminger Sea into 3 periods. The first period includes the moderate winters between 
2002 and 2007, the second period includes the two winters with intense mixing, 2007-2008 and 2008-2009, and the last period is the seemingly calm winter of 2009-2010.

\subsection{The winters between 2002 and 2007}

Mixed layers reaching about $400 \mathrm{~m}$ were common during most of these winters in the western part of the central Irminger Sea, which is not unexpected considering the moderate surface cooling. The day-to-day variability was high, mixed layers were observed intermittently with stratified profiles. This suggests that the mixed layers occurred in small cells, similar to the scheme proposed by Marshall and Schott (1999). The observed mixed layers were generally deepest at the location of LOCO 2 (450 to $620 \mathrm{~m}$ between 2002 and 2007) and somewhat shallower at the WHOI offshore mooring (380 and $355 \mathrm{~m}$ in 2002 and 2003) and the LOCO 3 mooring ( 280 to $550 \mathrm{~m}$ between 2003 and 2007). Due to an electrical short circuit in the MMP, the LOCO 2 record has a data gap between half of April 2007 and September 2007. However, since the surface cooling had already stopped at that time (Fig. 4) we do not expect the mixed layers to have exceeded $650 \mathrm{~m}$. Similarly, a blockage on the mooring cable caused the MMP of LOCO 3 to only record very short $(<100 \mathrm{~m}$ ) profiles after December 2006. The remaining profiles do show the evolution of the hydrographic properties at a depth of around $150 \mathrm{~m}$. Temperature dropped to about $5{ }^{\circ} \mathrm{C}$ and the density increased to about $\sigma_{0}=27.6 \mathrm{~kg} \mathrm{~m}^{-3}$. Although these signals are indicative of deepening mixed layers, the temperature (density) was still much higher (lower) than that of the deeper ( $>800 \mathrm{~m}$ ) mixed layers seen in the winters of 2007-2008 and 2008-2009, as we will show later. Also, during the previous 3 winters the mixed layers at LOCO 3 were much shallower than those observed at LOCO 2. The mixed layers that seem to have formed at the LOCO 3 location in early 2007 were probably also shallower than those observed at LOCO 2 . The shallower mixed layers were likely due to the stronger summer stratification at LOCO 3 (Figs. 2 and 5). However, all of the mixed layers observed between 2002 and 2007 extended well into the SPMW layer, strongly reducing the remaining stratification of the upper water column (Fig. 6). Nevertheless, during all of
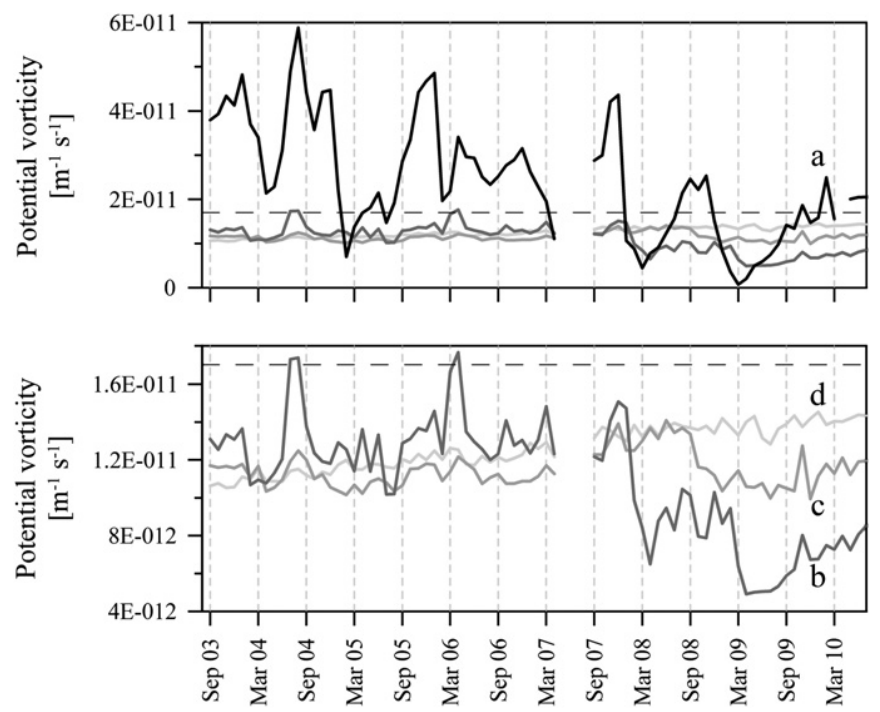

Fig. 6. Time series of PV observed by the LOCO 2 mooring. Depth average time series were derived for 4 depths levels; (a) 200 to $500 \mathrm{~m}$, (b) 500 to $1000 \mathrm{~m}$, (c) 1000 to $1500 \mathrm{~m}$ and (d) 1500 to $2000 \mathrm{~m}$. The time series were filtered using a running mean filter with a window of 3 months, to bring out the seasonal variability more clearly. The upper panel displays all 4 time series. The lower panel display the lower 3 time series, its $y$-axis covers the PV range between 0 and the dashed horizontal line in the upper panel. these winters a significant stratified layer remained present between the near-surface PV minimum created by local convective mixing and the intermediate PV minimum of the $\mathrm{LSW}_{2000}$ observed below $750 \mathrm{~m}$. Meanwhile, the intermediate PV and salinity minima gradually decayed during this period. Both observations suggest that the $\mathrm{LSW}_{2000}$ was neither renewed nor modified by local convection in these years.

\subsection{The winters of 2007-2008 and 2008-2009}

Clearly, these two following winters show a very different mixing regime. The much deeper mixed layers and lower PV values in the winters of 2007-2008 and 2008-2009 are the most striking features in Fig. 5. In the winter of 2007-2008, convective mixing exceeded $800 \mathrm{~m}$ at both LOCO moorings. Interestingly, mixed layers were deeper at LOCO 3, where mixed layers down to $1 \mathrm{~km}$ were observed. These deep mixed layers, generated despite the stronger stratification at the eastern side of the basin, are possibly related to convection cells that originated further west and were advected to the LOCO 3 location. Overall, the LOCO observations are in good agreement with ARGO float-derived mixed layer depth estimates (Våge et al., 2009). During the winter of 2007-2008 deep reaching ( $\sim 1600 \mathrm{~m})$ convection also occurred in the Labrador Sea primarily due to the strong surface forcing (Våge et al., 2009; Yashayaev and Loder, 2009). Since both basins are generally subject to the same passing synoptic storm systems, their inter-annual variability in surface cooling strongly covaries (as mentioned in Section 3), and thus the occurrence of convective mixing is expected to covary similarly.

Surprisingly, the Irminger Sea deep mixing was repeated during the following winter (2008-2009) despite the much weaker surface forcing (Fig. 4). The combination of remaining low stratification (Fig. 6), due to deep convective mixing during the preceding winter and subsequently low SSH in the centre of the Irminger Gyre, preconditioned the central Irminger Sea sufficiently to allow deep convective mixing under moderate forcing conditions. Mixed layers exceeding $800 \mathrm{~m}$ were observed in spring 2009 at the LOCO 2 mooring site (the LOCO 3 mooring had been terminated at that time). While the mixed layers at LOCO 2 were about as deep as during the previous winter, the 2008-2009 value of the PV minimum was significantly lower. Time series of monthly mean PV between 200 and 500 m (Fig. 6) show a minimum of $0.710^{-12} \mathrm{~m}^{-1} \mathrm{~s}^{-1}$ in March 2009 versus a minimum of $4.410^{-12} \mathrm{~m}^{-1} \mathrm{~s}^{-1}$ in March 2008. Fig. 6 also shows that the PV at depths between 1000 and 1500 was first affected in the spring of 2009. These low values of PV in the Irminger Sea are still commonly associated with LSW spreading from the Labrador Sea (Talley and McCartney, 1982) and not with local deep convective mixing.

The mixed layer properties were determined for the winters of 2007-2008 and 2008-2009 in order to characterize the water mass that was formed in the Irminger Sea under these conditions. In general, the mixed layers become colder and denser through winter (Fig. 7), as expected. Resulting temperatures and salinities are found around $4{ }^{\circ} \mathrm{C}$ and 34.92 , for both winters and both the LOCO 2 and LOCO 3 mooring location. It is not immediately obvious why all three $\theta$ and $S$ time series in Fig. 7 converge to such similar end points. For example, the initial temperature was about $1{ }^{\circ} \mathrm{C}$ higher at the LOCO 3 mooring due to the proximity of the warmer Irminger Current (Fig. 2). The similar end temperature may be explained by increased turbulent heat fluxes, due to the larger air-sea temperature difference, or advection of convective cells between the mooring locations. Also, the evolution of the salinity of the mixed layer shows different behaviors for the two winters. During the winter of 2007-2008, as well as during most of the previous winters (not shown), the salinity of the 

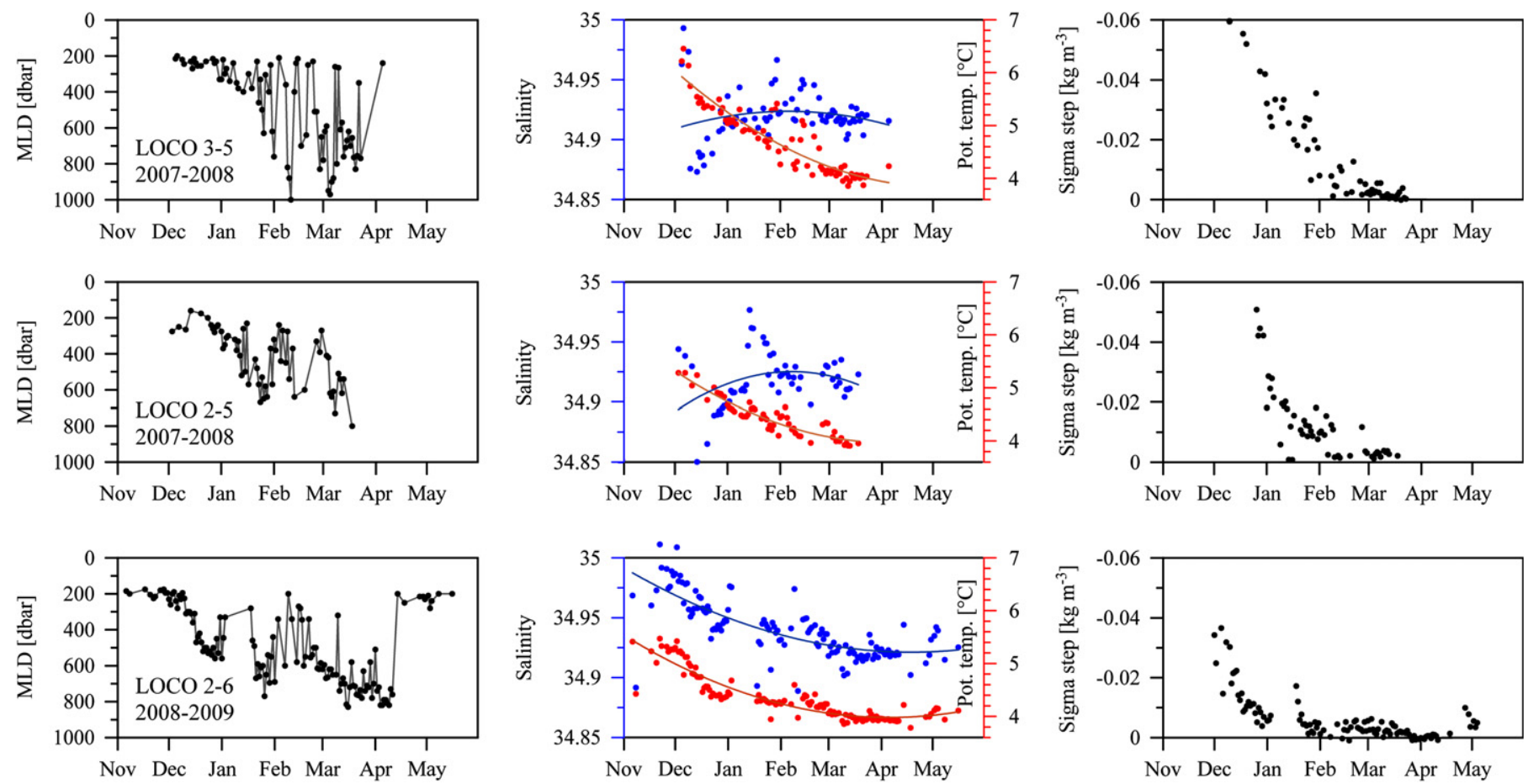

Fig. 7. Evolution of mixed layer depth and mixed layer properties during the winters with mixed layers exceeding $800 \mathrm{~m}$. The gradual increase in mixed layer depth (left panels) during winter ( 1 Nov to 31 May) is shown for the LOCO 2 and LOCO 3 moorings in the winters of 2007-2008 (upper and middle panels) and the LOCO 2 mooring in the winter of 2008-2009 (lower panels). The red symbols in the middle panels denote temperature, blue symbols denote salinity. The density gradient below the mixed layer, or sigma step, is defined as the difference in density between the mixed layer and the undisturbed profile 50 dbar below the bottom of the mixed layer, and is shown in the right panels.

mixed layer increased. By contrast, during the winter of 20082009 the salinity decreased. The difference in initial salinity is likely due to conditions in the near-surface layer. The hydrographic section, surveyed in September 2007 (Fig. 2), showed a fresh layer with salinity below 34.80 in the upper $40 \mathrm{~m}$ extending across nearly the entire width of the basin. The upper part of the time series of salinity of the LOCO 2 mooring also indicate the presence of a fresh surface layer before the winter of 2007-2008. This was likely the main cause of the low initial salinity of the mixed layers in the winter of 2007-2008 (Fig. 7). The LOCO 2 time series shows that much more saline water was present in the upper water column at the beginning of the winter of 2008-2009. While the initial salinity may differ between winters, the salinity of the mixed layers at the end of winter is largely determined by the thick layer of SPMW present in the upper $\sim 500 \mathrm{~m}$ of the water column in the central Irminger Gyre (Fig. 2). Since the interannual variability of the SPMW is relatively low compare to that of the surface layer, the salinities of mixed layers in subsequent years are likely to converge.

The shallower mixed layers observed in the winters prior to 2008 resulted in similar salinities. Mixed layer salinities in the Irminger Sea are generally higher than the salinity associated with the relatively fresh LSW in the Labrador and Irminger Seas (Yashayaev, 2007; Falina et al., 2007). However, between the winters of 2007-2008 and 2008-2009 there appeared to arrive a considerable volume of fresher water in the depth range of 200 to $1200 \mathrm{~m}$. This low salinity $(\sim 34.86)$ water remained present through summer and appeared to be located directly underneath the high salinity SPMW in the fall of 2008. Thus, as the mixed layers deepened in the winter of 2008-2009 they incorporated a larger volume of low salinity water into the initially saline mixed layer, which resulted in a decreasing salinity (Fig. 7). The arrival of the low salinity water may also have halted the decay of the intermediate salinity minimum. We will try to explain the origin of the low salinity water by means of the Argo float profiles in Section 5 .

\subsection{The winter of $2009-2010$}

The last winter included in the LOCO 2 record, the winter of 2009-2010, was only partly observed due to difficulties with the MMP. Many profiles were incomplete, missing mostly the upper part of the water column. As a consequence, few mixed layers could be identified in these shortened profiles. The available complete profiles showed mixing down to about $360 \mathrm{~m}$. There is, however, a reasonable amount of data below $500 \mathrm{~m}$, allowing the PV values to be investigated there. If mixing had been substantial in the winter of 2009-2010, we would expect to see a strengthening of the PV minimum around $500 \mathrm{~m}$ similar to the previous two winters, possibly followed by subduction of the PV minimum to intermediate levels. Fig. 5, however, shows no indication of a change in $\mathrm{PV}$, other than the gradual decline of the PV minimum remaining from the winter of 2008-2009. The time series of PV in Fig. 6 also indicate increasing PV values at all depth levels through 2009-2010. Thus we assume that convective mixing did not exceed $400 \mathrm{~m}$ during this last winter, similar to the conditions in the winters between 2002 and 2007. This apparently weak mixing would agree with the moderate heat loss over the Irminger Sea during the winter of 2009-2010 seen in the OAflux time series (Fig. 4).

Because of the limited data retrieval in the upper water column in the winter of 2009-2010, Argo float data were used to further investigate the intensity of convective mixing in this winter. Also, float data cover a wider area, thus it allows us to assess the representativeness of the mooring data in the winters of 2007-2008 and 2008-2009 when intense mixing was observed. However, due to their 10 day cycle and the relatively short convective mixing period (a few months with mixed layers 
exceeding $200 \mathrm{~m}$ ) a float will typically sample only a few deep mixed layers each winter. Fig. 8 illustrates the distributions of mixed layer depths observed by floats between January 2007 and December 2010 in the area $51^{\circ} \mathrm{N}$ to $67^{\circ} \mathrm{N}$ by $60^{\circ} \mathrm{W}$ to $30^{\circ} \mathrm{W}$, which includes both the Labrador and Irminger Seas. Shallow mixed layers $(<400 \mathrm{~m})$ dominate the data set of 5579 float profiles. These shallow mixed layers are mostly observed during the summer months and along the stably stratified boundaries of the study region. Profiles recorded between 1 November and 30 April, the period during which most mixed layers were observed by the moorings, were selected for the three winters of interest. The distributions of mixed layers depths for these winters (Fig. 8) confirm the observations of the moorings. During the winter of 2007-2008 the deepest mixed layers were observed. The bulk of the mixed layers exceeding $1000 \mathrm{~m}$ were found in the central
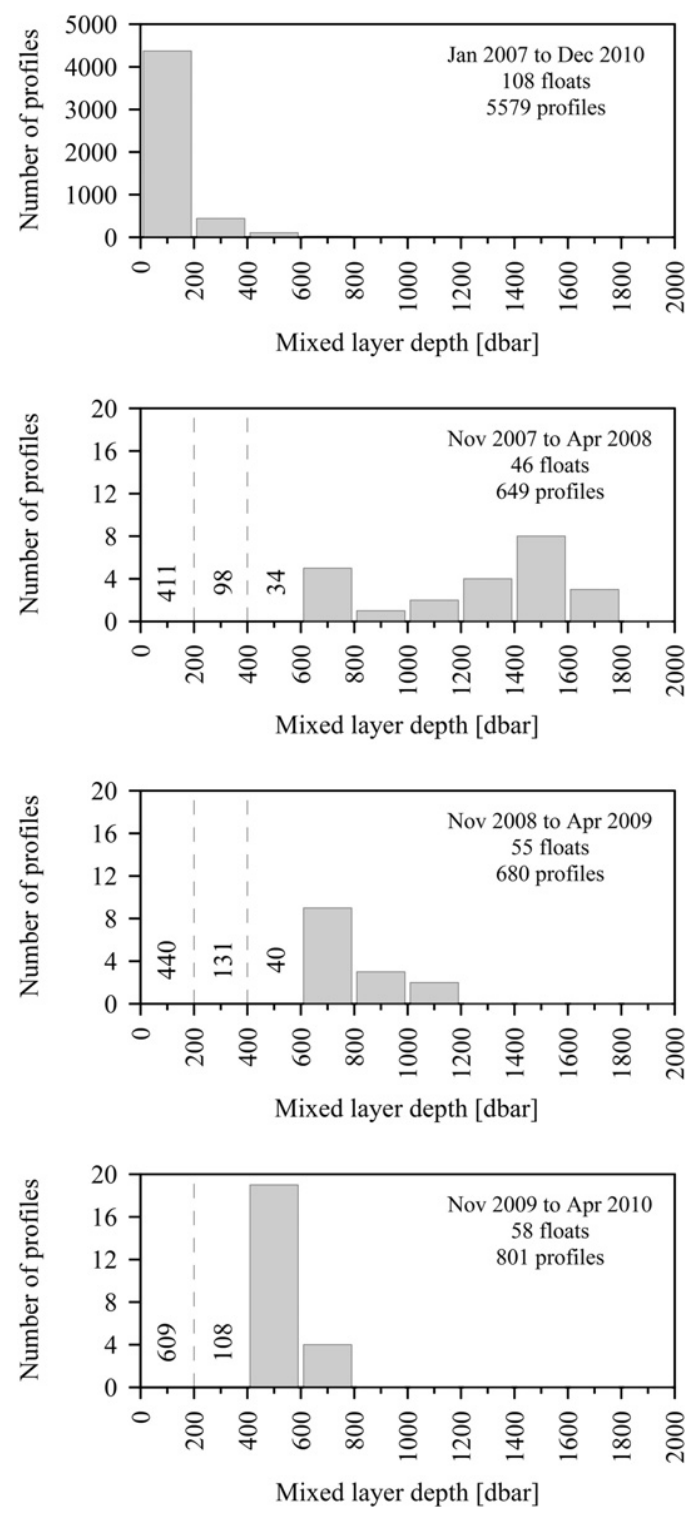

Fig. 8. Mixed layer depth distributions for the Argo float data set. The top panel illustrates the distribution for the entire data set which includes all (quality checked) profiles between $51^{\circ} \mathrm{N}$ to $67^{\circ} \mathrm{N}$ and $60^{\circ} \mathrm{W}$ to $30^{\circ} \mathrm{W}$ and between January 2007 and December 2010. The lower three panels illustrate the mixed layer depth distribution for the subsets of float data for the winter of 2007-2008 (second panel), 2008-2009 (third panel) and 2009-2010 (fourth panel). The $y$-axis of these three panels have been adjusted to bring out the distribution of mixed layers deeper than $600 \mathrm{~m}$ more clearly. The distributions of the mixed layers shallower than $600 \mathrm{~m}$ are indicated by numbers rather than bars.
Labrador Sea, with some individual profiles found south of Cape Farewell and near the LOCO 2 mooring position. This agrees with the findings of Våge et al. (2009) who used a similar float data set. During the following winter, that of 2008-2009, only two mixed layers exceeding $1000 \mathrm{~m}$ were found (Fig. 8). These mixed layers were observed in the central Labrador Sea. Mixed layers exceeding $800 \mathrm{~m}$ were observed in both the Labrador Sea and the southern Irminger Sea. No floats were present near $(<100$ nautical mile) the LOCO 2 mooring location during the period when mixed layers were recorded by the MMP there. The distribution of mixed layer depths of the winter of 2009-2010 (Fig. 8) clearly shows that the more shallow mixed layers (0 to $200 \mathrm{~m}$ and 200 to $400 \mathrm{~m}$ ) were dominant. No mixed layers exceeding $1000 \mathrm{~m}$ were observed during this last winter. This confirms our expectation of a weak convective mixing regime which was based on the limited mooring data and the moderate surface heat fluxes during this winter.

\subsection{Restratification in spring and summer}

The restratification is only briefly described here, mainly where it concerns the rebuilding of the stratification and the advection of the convective product after winter. Restratified profiles appear intermittently between profiles with mixed layers and, more continuously, in spring and summer. This restratification of the upper $500 \mathrm{~m}$ is clearly visible in Figs. 5 and 6. The increase in stability of the water column is mainly caused by an increase in temperature in the upper layers. This increase in temperature over a thick layer of the water column is visible as a seasonal cycle in sea surface height (Fig. 3). The seasonal cycle in SSH was more or less constant between 2002 and 2006. However, convective mixing during the winters of 2007-2008 and 20082009 and the associated heat loss of the water column strongly lowered the SSH. SSH summer values observed after the winters of 2007-2008 and 2008-2009 were low relative to previous summers, mostly because the water column had not totally regained its former heat content (Fig. 3).

Absorption of solar radiation may have played a role in the observed increase in temperature, but more important are lateral fluxes by eddies from the Irminger Current. This is similar to the process described by Katsman et al. (2004) in the Labrador Sea. There the eddies are shed by the deeper warm and saline branch of the West Greenland Current. Comparison of the temperature and salinity characteristics of the upper water in our mooring time series with AR7E survey data from 2007 to 2009 suggest that the water that restratifies the central Irminger Sea originates from the warmer, more saline Irminger Current flowing along the western flank of the Reykjanes Ridge. Below $500 \mathrm{~m}$ other processes seem to be at work. Before 2008, the intermediate PV minimum is visible near $750 \mathrm{~m}$ (Fig. 5), which is generally associated with the LSW $_{2000}$ class from the Labrador Sea. The variability in PV in this layer is most pronounced following the winters of 2007-2008 and 2008-2009. At first sight, the decrease in PV appears to be connected to the subduction of the near surface PV minimum, which would also fit the theory of Marshall and Schott (1999). However, a side by side comparison of the time series of PV and salinity (Fig. 9) leads to a different interpretation. The intermediate low PV columns seen at the end of 2008 are in fact related to much fresher (and apparently quite homogeneous) water arriving at the LOCO 2 location. The difference in salinity (about 0.06 ) is relatively large and indicates that this water is formed under conditions different from those observed at the LOCO 2 and LOCO 3 mooring locations. This fresher water is first seen just after mixing stops in the spring of 2008 (around profile number 203, April 1st 2008). This is too soon to be LSW from the 


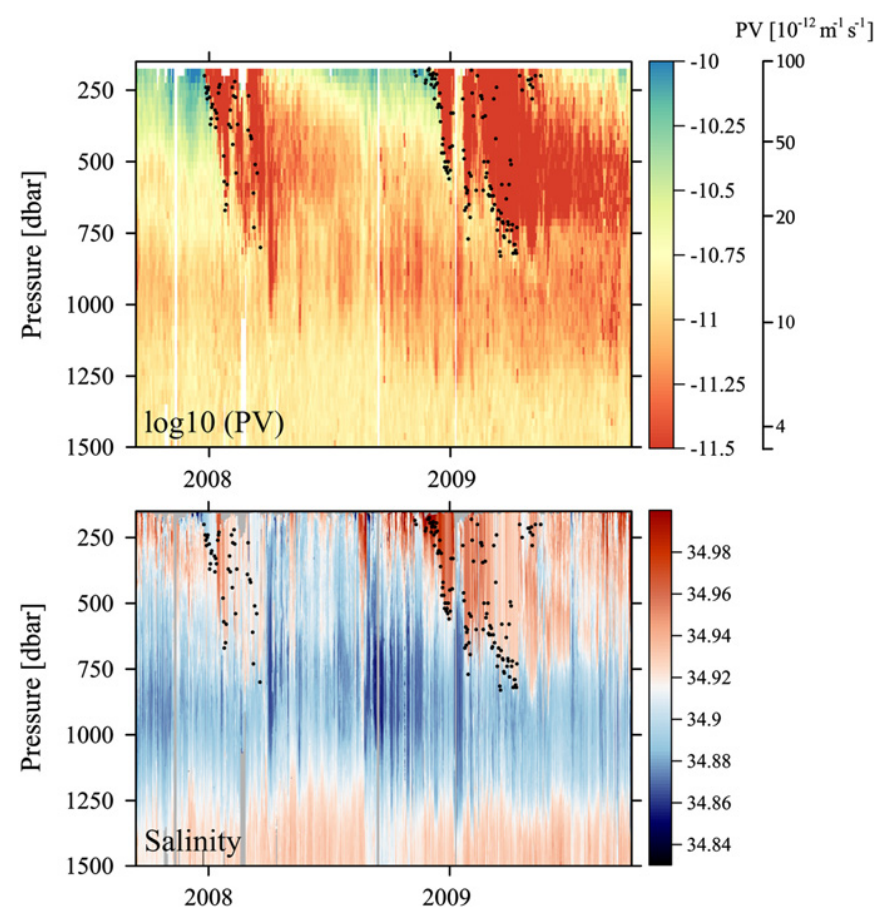

Fig. 9. Time series of PV (top panel) and salinity (bottom panel) of the LOCO 2-5 and LOCO 2-6 deployments between September 2007 and October 2009. The relatively fresh water can be recognized by the dark blue colours at intermediate depth ( $\sim 1000 \mathrm{dbar})$ throughout the deployments and at shallower depths in the summer of 2008. The mixed layer depths determined from the profiles are indicated by the black dots.

central Labrador Sea (Talley and McCartney, 1982; Pickart et al., 2003; Yashayaev, 2007; Van Aken et al., 2011).

\section{Discussion: Is LSW formed in the Irminger Sea?}

The mooring observations in the central Irminger Sea have shown that deep convection, reaching down to the level associated with LSW, does occur in the Irminger Sea during favorable conditions, such as in the winters of 2007-2008 and 2008-2009. The convective mixing drastically reduces local the PV values, especially in 2009 (Fig. 6). Such low PV values $(0.7$ $10^{-12} \mathrm{~m}^{-1} \mathrm{~s}^{-1}$ ) were previously mainly associated with LSW formed in the Labrador Sea, although a PV minimum was found in the central Irminger Sea by Pickart et al., 2003. However, the locally formed convective water (Fig. 7) appears to be more saline and warmer than the LSW reported to be formed in the Labrador Sea in the winter of 2007-2008 (approximately $3.4{ }^{\circ} \mathrm{C}$ and 34.85 based on the figures in Yashayaev and Loder (2009)). Here we must note that salinity values found in the Labrador Sea in the winter of 2007-2008 are also relatively saline compared to previous years. Avsic et al. (2006) describe salinity values ranging from 34.81 to 34.83 between 1995 and 2003 at the K1 mooring location near the former OWS Bravo site. A salinity of 34.85 was recorded in 2005, which is comparable to the values described here. Increases in salinity (and temperature) are seen throughout the Subpolar Gyre in the recent decade (Sarafanov et al., 2007; Van Aken et al., 2011). Thus, any water mass formed by convection in either the winter of 2007-2008 or 2008-2009 in this region will be unlike the LSW of the 1990s in terms of salinity.

Although the mixed layers in the Irminger Sea are relatively saline, vertically homogenous and less saline water is seen to arrive at intermediate depths in the Irminger Sea in early April
2008 and continues to freshen the upper $1200 \mathrm{~m}$ of the water column over the following summer (Fig. 9). In summer surveys this intermediate, low-PV and low-salinity water is usually identified as LSW from the central Labrador Sea. However, in order to arrive just at the end of winter, this water must have been formed in close proximity to the mooring. If the relatively fresh water that reinforces the intermediate PV minimum is not LSW formed in the central Labrador Sea, but is formed by convection as its PV value suggests, then the region south of Cape Farewell is a likely candidate (Bacon et al., 2003). More freshwater is available there, due to occasional retroflection of the East Greenland Current (Holliday et al., 2007), although the amount of freshwater brought offshore by the retroflection is unknown. The Cape Farewell region is also mentioned by Våge et al. (2009) as a convection area in the winter of 2007-2008. This area is favorable for convection because of its low SSH (Lavender et al., 2000), trapping the water within a local cyclonic recirculation.

Float data can shed more light on the horizontal distributions of temperature and salinity of the intermediate water (at around $750 \mathrm{~m}$ depth). Fig. 10 illustrates the distributions of PV, $S$ and $\theta$ during the winter of 2007-2008. Here data from the 3 months during which most mixed layers were observed (February-April) are used. One major convection area, the central Labrador Sea, and two minor convection areas, southwest of Cape Farewell and the central Irminger Sea, appear in the PV distribution. The major convection area is associated with the lowest temperatures and salinities, while the Irminger Sea is warmest and most saline. However, these gradients in $S$ and $\theta$ are density compensating (Fig. 11), implying that the various convective products will be found at similar depths after restratification. Only the deepest mixed layers, found in the PV minimum in the Labrador Sea, will likely form denser water and will be found underneath the convective products of the wider Subpolar Gyre area.

This is illustrated in more detail by the individual float profiles in Fig. 11. These profiles, showing the deepest mixed layers recorded by 3 floats, are representative of the 3 convection areas. Their positions are shown in the top panel of Fig. 11. Also shown are the deepest 5 mixed layers recorded by the LOCO 2 mooring in the same winter. The $\theta, S$-diagram shows that the warmest and most saline mixed layers were recorded by the mooring in the central Irminger Sea. South-southeast of Cape Farewell, float 6900240 (in red) recorded somewhat fresher and colder mixed layers. Closer to the central Labrador Sea, south-southwest of Cape Farewell, float 4900537 (in green) observed the mixed layers with the lowest salinity of all three floats. The lowest temperatures and highest densities $\left(\sigma_{0}=27.748\right.$, standard deviation $<0.001 \mathrm{~kg} \mathrm{~m}^{-3}$ ) were recorded by float 4900500 (in blue) in the southeastern part of the Labrador Sea. Again, the density of the mixed layers recorded by the LOCO 2 mooring and the two floats closest to Cape Farewell are quite similar $\left(27.707 \pm 0.004 \mathrm{~kg} \mathrm{~m}^{-3}\right.$ for float $6900240,27.716 \pm 0.005 \mathrm{~kg} \mathrm{~m}^{-3}$ for float 4900537 and $27.721 \pm 0.005 \mathrm{~kg} \mathrm{~m}^{-3}$ for LOCO 2, respectively). Hence, all of these mixed layer products can be found at similar depths after restratification. The colder convective product from the more central Labrador Sea is clearly of a different, higherdensity class.

The fresher water that was seen to arrive at the LOCO 2 location around day 200 of the LOCO 2-5 deployment (in April 2008) had a salinity of 34.86 and a potential temperature of $3.5^{\circ} \mathrm{C}$. These values are at the density level of the mixed layers observed by float 4900537 (in green) south-southwest of Cape Farewell. The profiles plotted in Fig. 9 were first observed in late March/early April, but this float recorded shallower mixed layers with a similar salinity already in February. The time lag between the mixed layers observed by the float and the arrival of this fresher (intermediate) water at the mooring (seen first at April 1st) 

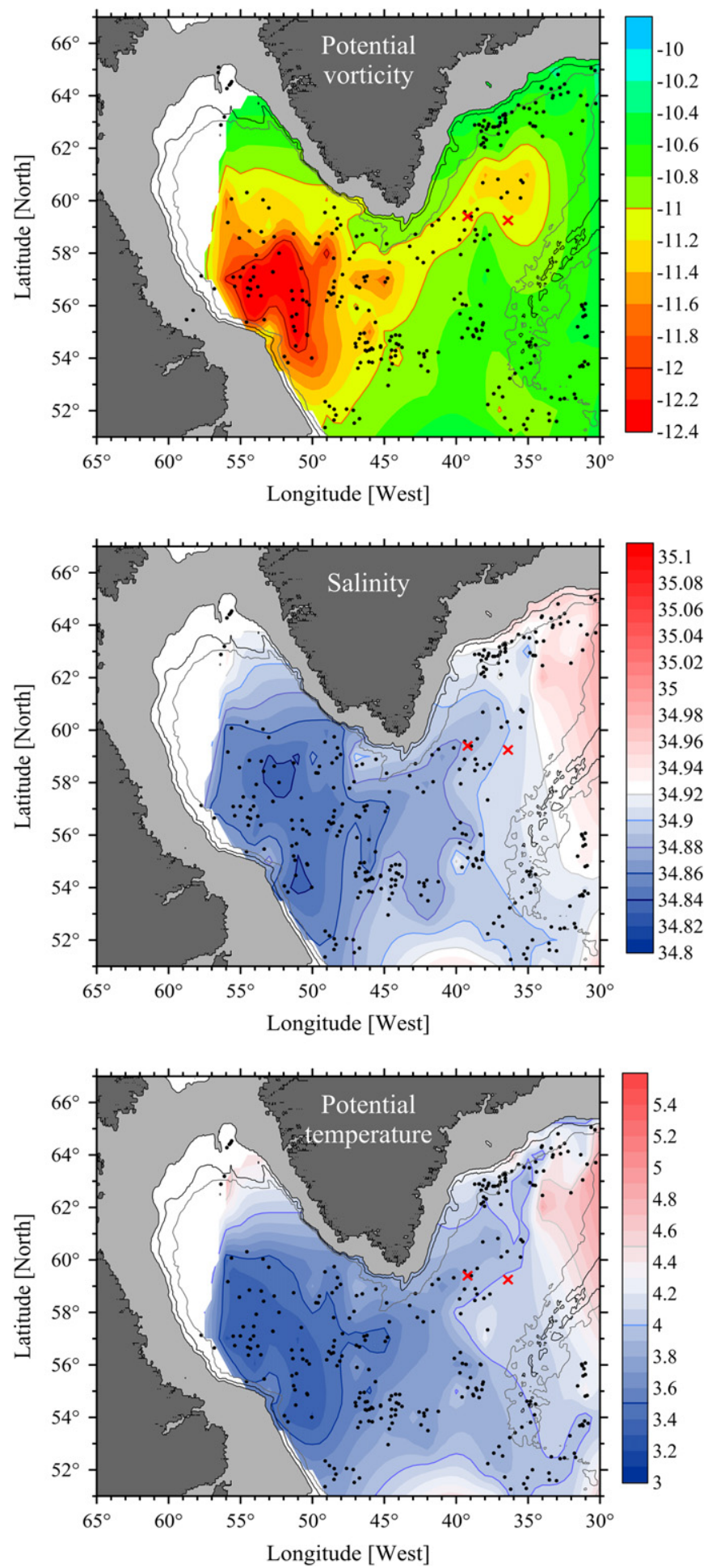

Fig. 10. Horizontal fields of potential vorticity (top panel), salinity (middle panel) and potential temperature (lower panel) at $750 \mathrm{~m}$ depth derived from float profiles recorded in early 2008 (Feb-Apr). Positions of float profiles are indicated by black dots. The LOCO 2 and three mooring locations are indicated by the red crosses. Topography shallower than $750 \mathrm{~m}$ has been blanked by light grey colours, the 1500 and $2250 \mathrm{~m}$ isobaths have been drawn in grey lines. The interpolation of the fields was done by a natural neighbour gridding method. Caution must be taken with the interpretation where float data are scarce. The PV distribution shows the three convection areas. The major convection area is the central Labrador Sea where PV $<1 \times 10^{-12} \mathrm{~m}^{-1} \mathrm{~s}^{-1}$ (red line). The two other convection areas are found southwest of Cape Farewell and in the central Irminger Sea. Both these areas are enclosed in the isoline of $P V=1 \times 10^{-11} \mathrm{~m}^{-1} \mathrm{~s}^{-1}$ (orange line). The lowest temperatures and salinities are found in the Labrador Sea convection area.
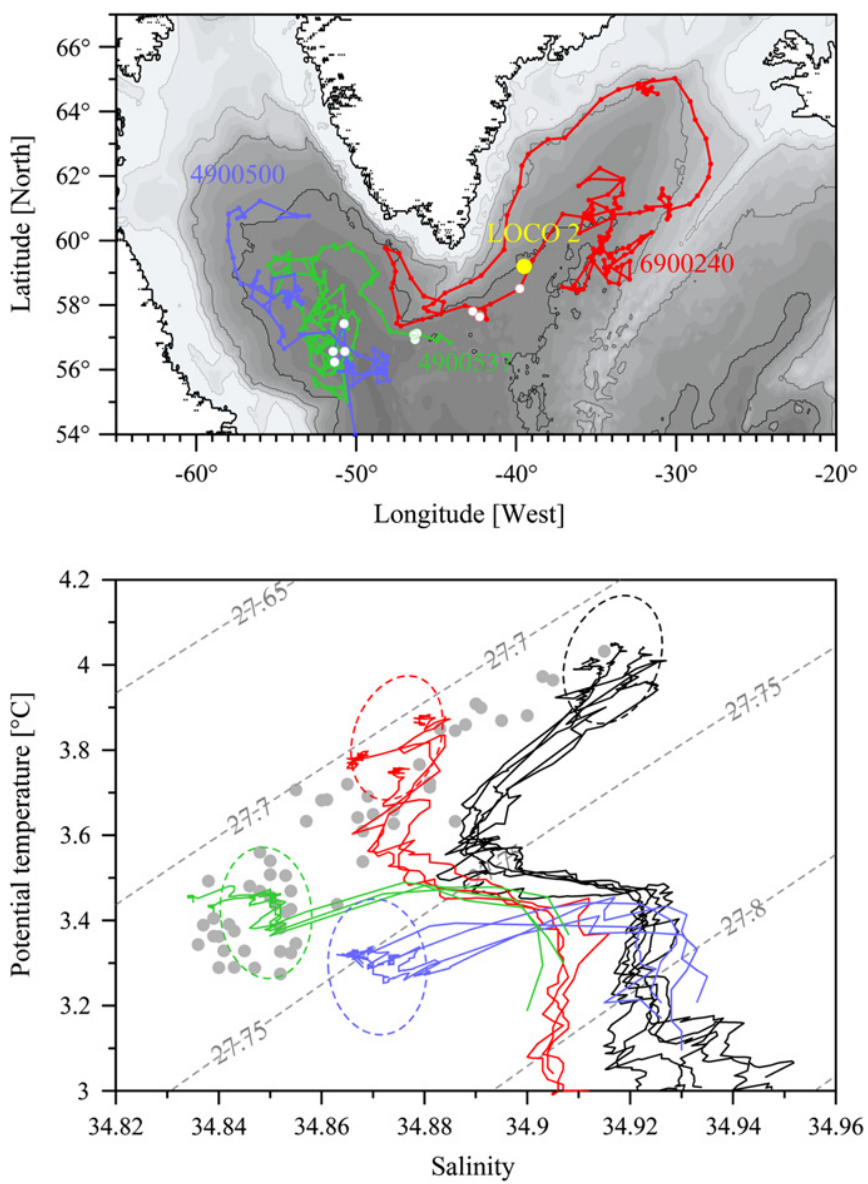

Fig. 11. Float data from 3 floats circulating through the Labrador and Irminge Seas. The upper panel illustrates the float tracks and the locations where the floats observed the deepest mixed layers (white circles). The position of the LOCO 2 mooring is indicated by the yellow circle. The lower panel illustrates the $\theta, S$ characteristics of the float and MMP profiles (in black) that included deep mixed layers in the winter of 2007-2008. The colours of the float profiles correspond the colours used in the upper panel for the different floats. The part of the profiles corresponding with the mixed layer is highlighted by the dashed ellipses. Also shown are the mean potential temperature and salinity values at $750 \mathrm{~m}$ depth (grey dots) for the floats enclosed by the $P V=1 \cdot 10^{-11} \mathrm{~m}^{-1} \mathrm{~s}^{-1}$ isoline in the upper panel of Fig. 10. Isopycnals $\left(\sigma_{0}\right.$ intervals of $0.05 \mathrm{~kg} \mathrm{~m}^{-3}$ ) are drawn with dashed grey lines.

is short. However, the track of the nearby float 6900240 (in red) demonstrates that water at intermediate depths can be transported from the area south of Cape Farewell to the central Irminger Sea quite rapidly. It took this float 9 cycles (90 day) to travel from a location near that of the mixed layers observed by float 4900537 (southwest of Cape Farewell) to a position close to the LOCO 2 mooring. The variation in distance between the locations of these nine cycles shows that the float experienced a large range of advection velocities along the way, 2 to $13 \mathrm{~cm} \mathrm{~s}^{-1}$ assuming linear advection paths between these 10 float positions. It is probable that the first mixed cells from south of Cape Farewell are advected to the central Irminger Sea within 3 months. Following this branch of the Subpolar Gyre further upstream leads to the larger reservoir of fresher water further away, in the central Labrador Sea. This large reservoir was probably responsible for the continued presence of relatively fresh water at the location of the LOCO 2 mooring between $\sim 200$ and $1200 \mathrm{~m}$ throughout summer and fall (Fig. 9).

Much of the upper part of this fresh layer in the Irminger Sea was replaced by more saline water during the local convective mixing in the following winter (2008-2009), leaving only the intermediate salinity minimum intact. This is reflected in the 

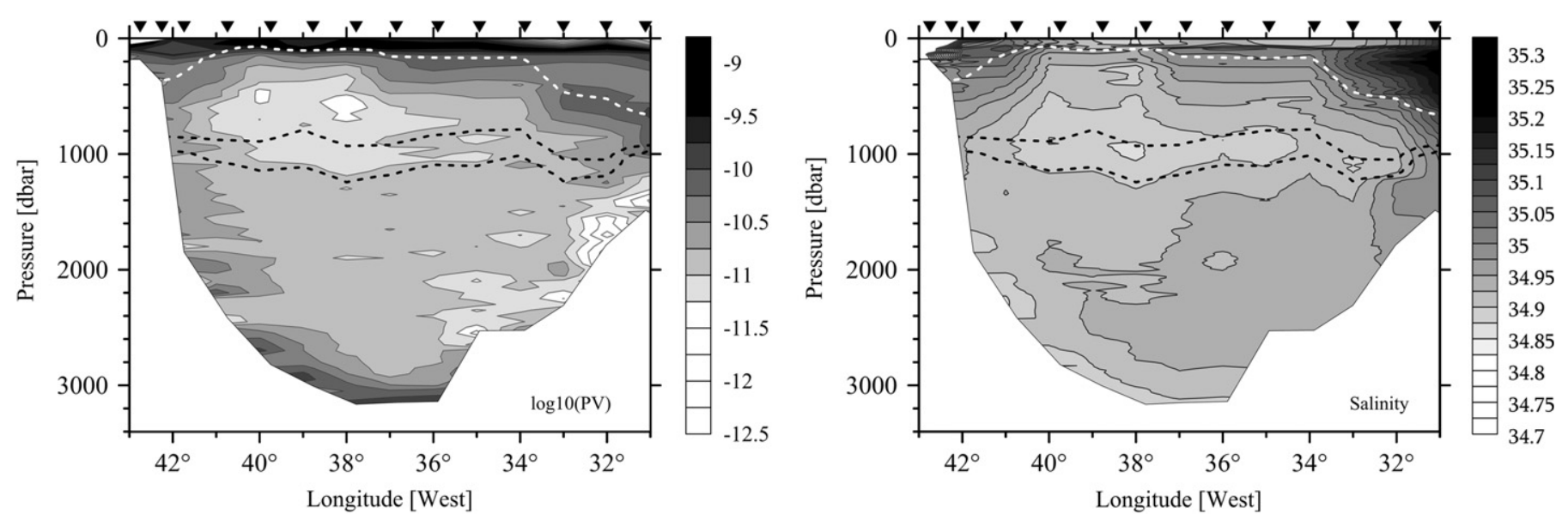

Fig. 12. Longitude - pressure distributions of potential vorticity (PV) and salinity from the hydrographic section in October 2009 observed by the RV Pelagia. The salinity distribution is also shown in colour in Fig. 2. The positions of the CTD stations are marked by the triangles on top. The PV (left panel) is plotted is as log function, with a line interval of $1 / 4$. The isohalines (right panel) are drawn with an interval of 0.025 . Three isopycnals are drawn in these panels. The $27.6 \mathrm{~kg} \mathrm{~m}^{-3}$ isopycnal (white dashed line), which indicated the density of the mixing layer in the central Irminger Sea at the beginning of winter, and the $27.73 \mathrm{~kg} \mathrm{~m}{ }^{-3}$ isopycnal (black dashed line), which is the approximate density of the mixed layers in the central Irminger Sea at the end of the winter 2008-2009. The third isopycal (lower black dashed line) is the $27.75 \mathrm{~kg}^{-3}$ isopycnal, which is associated with the convected product observed by float 5900500 in the central Labrador Sea. The PV minimum is found above the $27.73 \mathrm{~kg} \mathrm{~m}^{-3}$ isopycnal and is likely the remainder of local mixing in the previous winter. The salinity minimum (salinity $\sim 34.875$ ) is found below this isopycnal but above the isopycnal of the central Labrador Sea convective product.

hydrographic survey of October 2009 (Figs. 2 and 12). The PV minimum (Fig. 12) can be found between the isopycnal that corresponds to the density of the first observed mixed layers $\left(\sim 27.6 \mathrm{~kg} \mathrm{~m}^{-3}\right)$ and the isopycnal that corresponds to the deepest mixed layers observed in the Irminger Sea $\left(\sim 27.73 \mathrm{~kg} \mathrm{~m}^{-3}\right.$, slightly denser than the mixed layers observed in the winter of 2007-2008). The salinity minimum is found below the latter isopycnal, but above the density of the mixed layers observed by float 4900500 in the central Labrador Sea $\left(\sim 27.75 \mathrm{~kg} \mathrm{~m}^{-3}\right)$. The value of the salinity minimum, around 34.875 , also matches the salinity observed in these Labrador Sea mixed layers (Fig. 11). Thus the volume of water with low PV values $\left(<10 \times 10^{-12} \mathrm{~m}^{-1} \mathrm{~s}^{-1}\right)$ in the central Irminger Sea consists of several convective products. Some of these products can be separated or identified by their different densities, for example the denser product from the central Labrador Sea. The other convective products shown here, observed by the LOCO moorings and floats 4900537 and 6900240 , have very similar densities and may blend more easily. No arrival of fresher water is seen after the winter of 2008-2009. The float data also showed that mixing was generally less intense (deep) during this winter (Fig. 8). Thus, although the convective products formed in the Irminger Sea in recent years are significantly more saline than the Labrador Sea Water from the central Labrador Sea, they do alter the local hydrography in the upper $750 \mathrm{~m}$ and add to the PV minimum found in the centre of the basin.

Whether local convection also altered the hydrography of the Irminger Sea in the early 1990s, as Pickart et al. (2003) and Våge et al. (2011) suggested, cannot be confirmed by the time series presented here. The mooring records suggest that the Irminger Sea has the potential to convect much deeper than the $1 \mathrm{~km}$ observed in 2008. The density difference between the mixed layer and the undisturbed profile just below the mixed layer decreased strongly during both the winters of 2007-2008 and 2008-2009, until the density difference nearly disappeared at the end of winter (Fig. 7). In fact, the depth of the deepest mixed layers could be determined only from the temperature and salinity profiles, as the density profiles were nearly homogeneous. This suggests that the deepening of the mixed layer did not stop due to a remaining threshold in the density stratification (no remaining significant convective resistance). Rather, the surface cooling ceased or weakened sufficiently for restratification from the surrounding warmer boundary currents to take over. Had the stronger preconditioning in the winter of 2008-2009 coincided with the strong heat losses of the winter of 2007-2008, mixing could have reached much deeper than observed (similar to the model used by Pickart et al. (2003)). A distinct homogeneous water mass formed in the Irminger Sea might have then remained at the level of the LSW to be found in the hydrographic sections the following summer.

Irrespective of the precise characteristics of the resulting mixing products, convective mixing in the Irminger Sea can have an important effect on the Atlantic meridional overturning circulation. Convective mixing is an effective method to remove heat from a thick layer of water. The amount of heat removed does not only depend on the thickness of this layer and its final temperature, but also on the amount of heat initially present in the water column. Deeper mixing may occur in the Labrador Sea, but the water column in the Irminger Sea is initially much warmer. Indeed, Fig. 3 already showed that much heat was lost from the upper layers of the Irminger Sea in the winters of 20072008 and 2008-2009. A simple calculation can illustrate the relative importance of Irminger Sea convection. Fig. 13 shows fully stratified profiles from summer and mixed profiles from winter in the Labrador Sea and the Irminger Sea. For the central Labrador Sea float profiles, which extend to the surface, are shown. For the central Irminger Sea MMP and CTD profiles are shown. The MMP profile illustrates the coldest mixed layer observed by the LOCO 2 mooring. Since this MMP profile did not extend to the surface, a straight line with constant temperature was fitted to the mixed layer. Two fully stratified profiles are shown for the Irminger Sea. A shipboard CTD profile, which does extend to the surface, and an MMP profile from the LOCO 2 mooring which illustrates the representativeness of the CTD profile. The difference in heat content is the surface area between the mixed and stratified profiles, the integral of $\rho c_{P} \mathrm{~d} T(z) \mathrm{d} z$ over the depth of the mixed layer (with $\rho$ density, $c_{P}$ the heat capacity and $T(z)$ the vertical temperature profile). This leads to an estimated heat loss of $\rho c_{P} \cdot 620 \mathrm{~J} \mathrm{~m}^{-2}$ for the Irminger Sea and $\rho c_{P} \cdot 750 \mathrm{~J} \mathrm{~m}^{-2}$ for the Labrador Sea profiles. The heat lost by convection in winter per unit area is of the same order of magnitude. Thus, the main difference in heat lost to the atmosphere by both basins likely depends more on the size of the 


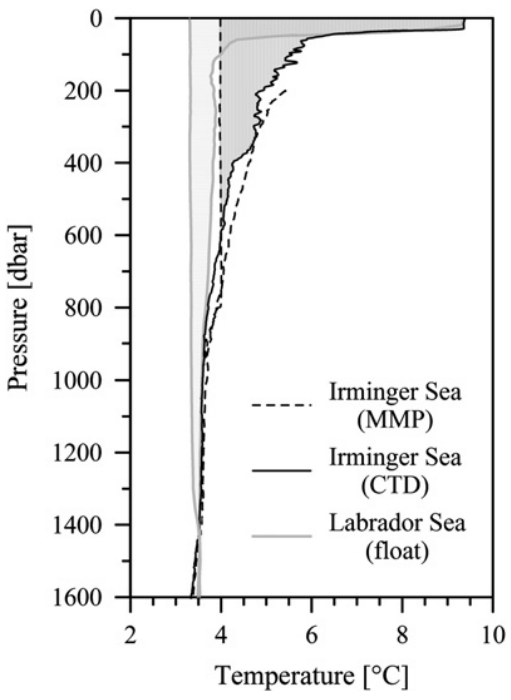

Fig. 13. Stratified and mixed profiles from the Labrador Sea (grey lines) and the Irminger Sea (black lines). Shown for the Labrador Sea are: the summer stratified profile from 2007 and the deepest mixed layer in the winter of 2007-2008, both recorded by float 4900500 . For the Irminger Sea the shipboard calibration CTD from fall 2007 (black solid line) is shown as the summer stratified profile. The summer MMP profiles from LOCO 2 (black dashed line) shows a similar stratification but cannot show the stratification in the upper $200 \mathrm{~m}$ because of the limited range of the profiler. The winter mixed layer profile from the MMP (black dashed line) was extended to the surface by a linear fit assuming a constant temperature (no tilt). The change in heat content between summer and winter in the two basins is illustrated by the highlighted areas.

convection area rather than the depth of it. Fig. 10 suggests that a considerable part of the Subpolar Gyre should be taken into account when investigating the North Atlantic heat budget.

\section{Conclusions}

Time series of hydrographic profiles from moorings in the central Irminger Sea show the occurrence of convective mixing through the thermocline in winter, reaching about 400 to 600 dbar between 2003 and 2007. During these winters the sea surface was subject to moderate winter cooling. The hydrographic and atmospheric conditions were sufficiently favourable to allow much deeper convection during the following two winters. During the first of these winters, the winter of 2007-2008, extremely strong heat fluxes forced deep convective mixing down to $1 \mathrm{~km}$ despite the presence of a considerable freshwater lid (Fig. 2). At that time convective mixing down to $1600 \mathrm{~m}$ also occurred in the Labrador Sea, several hundred $m$ deeper than had been seen in recent years (Våge et al., 2009; Yashayaev and Loder, 2009). Heat fluxes were lower during the subsequent winter, the winter of 2008-2009, but the initial stratification was weaker due to deep convective mixing during the preceding winter and an early start of winter cooling, allowing less time for restratification. This combination of circumstances led to an observed mixed layer depth of $800 \mathrm{~m}$ under moderate atmospheric forcing. The last winter included in this time series (2009-2010) was not well observed by the profiling instruments. However, the available float data indicate that convection was generally weak during this winter.

The properties of the deep mixed layers in the central Irminger Sea observed in the winters of 2007-2008 and 2008-2009 converge towards similar values at the end of the mixing season, despite different initial values. In the winters of 2007-2008 and 2008-2009 the typical final temperature and salinity of the convective product in the central Irminger Sea were found to be
$4{ }^{\circ} \mathrm{C}$ and 34.92, significantly warmer and more saline than the LSW formed simultaneously in the Labrador Sea $\left(3.4^{\circ} \mathrm{C}\right.$ and 34.85 , Yashayaev and Loder, 2009) although the density was very similar. Fresher water, around 34.86, was seen to arrive in spring 2008 at the LOCO 2 mooring location in the Irminger Sea. This early timing seems to exclude the arrival of LSW from the central Labrador Sea. A comparison with float data shows that this fresher water likely originated from an area south-southwest of Cape Farewell. Irminger Sea convective mixing in the following winter (2008-2009) eroded the upper part of this layer of relatively fresh water. This increased the salinity of the upper $800 \mathrm{~m}$ significantly, while strongly decreasing the planetary potential vorticity. No arrival of relatively fresh water was observed after this winter, hence the change in salinity stratification in the Irminger Sea persisted.

While the changes in local hydrography due to convective mixing in the Irminger Sea during the winters of 2007-2008 and 2008-2009 were relatively small (in volume and magnitude) compared to those observed in the Labrador Sea, they were nearly equal in terms of heat lost to the atmosphere per unit area (Fig. 13). The removal of the much stronger initial temperature stratification in the Irminger Sea implies a heat loss similar in magnitude to that of the central Labrador Sea, despite the generally shallower mixed layers. The near disappearance of the density gradient at the bottom of the Irminger Sea mixed layers as their depths approach $800 \mathrm{~m}$ suggests that little additional cooling is needed to achieve deeper mixed layer depths. However, in the observed winters cooling stopped as mixed layers reached $\sim 800 \mathrm{~m}$. Also, deep convective mixing in a series of successive cold winters, similar to those observed in the Labrador Sea in the early 1990s, may well be able to create a large volume of convective water with LSW characteristics in the Irminger Sea. A set of consecutive cold winters has yet to impact the Irminger Sea now that it is instrumented with year round moorings and floats.

\section{Acknowledgements}

The authors thank the reviewers, particularly the second reviewer, for their constructive comments. This study is part of the European Community's 7th framework programme (FP7/20072013) under grant agreement No. GA212643 (THOR: "Thermohaline Overturning - at Risk", 2008-2012). R.S.P. Received funding from the US National Science Foundation, grant OCE-0726640. The altimeter data were produced by Ssalto/Duacs and distributed by Aviso, with support from Cnes (http://www.aviso.oceanobs.com/ duacs/). Global ocean heat flux data were provided by the WHOI OAFlux project (http://oaflux.whoi.edu) funded by NOAA Climate Observations and Monitoring (COM) program. Argo data were collected and made freely available by the International Argo Program and the national programs that contribute to it. (http:// www.argo.ucsd.edu, http://argo.jcommops.org). The Argo Program is part of the Global Ocean Observing System.

\section{References}

Avsic, T., Karstensen, J., Send, U., Fischer, J., 2006. Interannual variability of newly formed Labrador Sea water from 1994 to 2005. Geophys. Res. Lett. 33, L21S02. doi:10.1029/2006GL026913.

Bacon, S., Gould, W.J., Jia, Y.L., 2003. Open-ocean convection in the Irminger Sea. Geophys. Res. Lett. 30, 1246. doi:10.1029/2002GL016271.

Bersch, M., 1995. On the circulation of the northeastern North Atlantic. Deep Sea Res. Part I 42 (9), 1583-1607. doi:10.1016/0967-0637(95)00071-D.

Bersch, M., Yashayaev, I., Koltermann, K.P., 2007. Recent changes of the thermohaline circulation in the subpolar North Atlantic. Ocean Dyn. 57, 223-235. doi:10.1007/s10236-007-0104-7. 
Bower, A.S., Lozier, M.S., Gary, S.F., Böning, C.W., 2009. Interior pathways of the North Atlantic meridional overturning circulation. Nature 459, 243-248. doi:10.1038/nature07979.

Brambilla, E., Talley, L.D., 2008. Subpolar Mode Water in the northeastern Atlantic: 1. Averaged properties and mean circulation. J. Geophys. Res. 113, C04025. doi:10.1029/2006JC004062.

Centurioni, L.R., Gould, J.W., 2004. Winter conditions in the Irminger Sea observed with profiling floats. J. Mar. Res. 62, 313-336. doi:10.1357/0022240041446209.

De Jong, M.F., (2010). Hydrographic variability in the Irminger Sea, PhD Thesis, Utrecht University, Utrecht, the Netherlands, pp. 208.

Doherty, K.W., Frye, D.E., Liberatore, S.P., Toole, J.M., 1999. A moored profiling instrument. J. Atmos. Oceanic Technol. 16, 1816-1829. doi:10.1175/15200426(1999)016 < 1816:AMPI > 2.0.CO;2

Doyle, J.D., Shapiro, M.A., 1999. Flow response to large-scale topography: the Greenland tip jet. Tellus A 51, 728-748. doi:10.1034/j.1600-0870.1996.00014.x.

Eden, C., Böning, C., 2002. Sources of Eddy Kinetic Energy in the Labrador Sea. J. Phys. Oceanogr. 32, 3346-3363. doi:10.1175/1520-0485(2002)032 $\langle 3346$ :SOEKEI $>2.0$. CO; 2 .

Falina, A., Sarafanov, A., Sokov, A., 2007. Variability and renewal of Labrador Sea Water in the Irminger Basin in 1991-2004. J. Geophys. Res. 112, C01006. doi:10.1029/2005JC003348.

Flatau, M.K., Talley, L.D., Niiler, P.P., 2003. The North Atlantic Oscillation, surface current velocities, and SST changes in the subpolar North Atlantic. J. Clim. 16 (14), 2355-2369. doi:10.1175/2787.1.

Hátún, H., Sande, A.B., Drange, H., Hansen, B., Valdimarsson, H., 2005. Influence of the Atlantic Subpolar Gyre on the thermohaline circulation. Science 309, 1841-1844. doi:10.1126/science.1114777.

Hátún, H., Eriksen, C.C., Rhines, P.B., 2007. Buoyant eddies entering the Labrador Sea observed with gliders and altimetry. J. Phys. Oceanogr. 37, 2838-2854. doi:10.1175/2007JPO3567.1.

Holliday, N.P., Meyer, A., Bacon, S., Alderson, S.G., de Cuevas, B., 2007. Retroflection of part of the East Greenland Current at Cape Farewell. Geophys. Res. Lett. 34. doi:10.1029/2006GL02985.

Holte, J., Talley, L., 2009. A new algorithm for finding mixed layer depths with applications to Argo data and Subarctic Mode Water formation. J. Atmos. Oceanic Technol. 26, 1920-1939. doi:10.1175/2009JTECH0543.1.

Katsman, C.A., Spall, M.A., Pickart, R.S., 2004. Boundary current eddies and their role in the restratification of the Labrador Sea. J. Phys. Oceanogr. 34, 1967-1983. doi:10.1175/1520-0485(2004)034 < 1967:BCEATR > 2.0.CO;2.

Killworth, P.D., 1983. Deep convection in the world ocean. Rev. Geophys. 21 (1), $1-26$.

Lavender, K.L., Davis, R.E., Owens, W.B., 2000. Mid-depth recirculation observed in the interior Labrador and Irminger seas by direct velocity measurements. Nature 407, 66-69. doi:10.1038/35024048.

Lazier, J.R.N., 1980. Oceanographic conditions at Ocean Weather Ship Bravo, 19641974. Atmos. Ocean 18 (3), 227-238. doi:10.1080/07055900.1980.9649089.

Lazier, J.R.N., Hendry, R., Clarke, R.A., Yashayaev, I., Rhines, P.B., 2002. Convection and restratification in the Labrador Sea, 1990-2000. Deep-Sea Res. I 49 (10), 1819-1835. doi:10.1016/S0967-0637(02)00064-X.

Marshall, J., Schott, F., 1999. Open-ocean convection: Observations, theory and models. Rev. Geophys. 37, 1-64. doi:10.1029/98RG02739.
McCartney, M.S., Talley, L.D., 1982. The Subpolar Mode Water of the North Atlantic. J. Phys. Oceanogr. 12, 1169-1188. doi:10.1175/1520-0485 (1982) $012<1169$ :TSMWOT $>2.0$. CO; 2 .

Moore, G.W.K., Renfrew, I.A., 2005. Tip jets and barrier winds; A QuickSCAT climatology of high wind speed events around Greenland. J. Clim. 18, 3713-3725.

Nansen, F., 1912. Das Bodenwasser und die Abkuhlung des Meeres. Int. Rev. Gesamten Hydorbiologie und Hydrographie Band V 1, 1-42.

Pickart, R.S., Torres, D.J., Clarke, R.A., 2002. Hydrography of the Labrador Sea during active convection. J. Phys. Oeanogr. 32, 428-457.

Pickart, R.S., Straneo, F., Moore, G.W.K., 2003. Is Labrador Sea Water formed in the Irminger Basin? Deep Sea Res. Part I 50 (1), 23-52. doi:10.1016/S09670637(02)00134-6.

Rhein, M., Kieke, D., Steinfeldt, R., 2007. Ventilation of the Upper Labrador Sea Water, 2003-2005. Geophys. Res. Lett. 34, L06603. doi:10.1029/ 2006 GL028540.

Sarafanov, A., Sokov, A., Demidov, A., Falina, A., 2007. Warming and salinification of intermediate and deep waters in the Irminger Sea and the Iceland Basin in 1997-2006. Geophys. Res. Lett. 34, L23609. doi:10.1029/2007GL031074.

Straneo, F., Kawase, M., Riser, S.C., 2002. Idealized models of slantwise convection in a baroclinic flow. J. Phys. Oceanogr. 32, 558-572.

Sverdrup, H.U., Johnson, M.W., Fleming, R.H., 1942. The Oceans: Their Physics, Chemistry, and General Biology, 1060 pp.. Prentice-Hall, Inc., Englewood Cliffs, NJ. USA.

Talley, L.D., McCartney, M.S., 1982. Distribution and circulation of Labrador Sea Water. J. Phys. Oceanogr. 12, 1189-1205. doi:10.1175/1520-0485(1982)012 $<$ 1189:DACOLS > 2.0.CO;2.

Våge, K., Pickart, R.S., Moore, G.W.K., Ribergaard, M.H., 2008. Winter mixed layer development in the Central Irminger Sea: the effect of strong, intermittent wind events. J. Phys. Oceanogr. 38, 541-565. doi:10.1175/2007JPO3678.1.

Våge, K., Pickart, R.S., Thierry, V., Reverdin, G., Lee, C.M., Petrie, B., Agnew, T.A., Wong, A., Ribergaard, M.H., 2009. Surprising return of deep convection to the subpolar North Atlantic Ocean in winter 2007-2008. Nat. Geosci., 382. doi:10.1038.

Våge, K., Pickart, R.S., Sarafanov, A., Knutsen, Ø., Mercier, H., Lherminier, P., van Aken, H.M. Meincke, J., Quadfasel, D. 2011. The Irminger Gyre: circulation, convection, and interannual variability. Deep Sea Res. Part I 58, 590-614. doi:10.1016/j.dsr.2011.03.001.

Van Aken, H.M., de Jong, M.F., Yashayaev, I., 2011. Decadal and multi-decadal variability of Labrador Sea Water in the northern North Atlantic Ocean derived from tracer distributions: heat budget, ventilation, and advection. Deep Sea Res. Part I 58 (5), 505-523. doi:10.1016/j.dsr.2011.02.008.

Volkov, D.L., van Aken, H.M., 2003. Annual and interannual variability of sea level in the northern North Atlantic Ocean. J. Geophys. Res. 108 (C6), 3204. doi:10.1029/2002JC001459.

Yashayaev, I., 2007. Hydrographic changes in the Labrador Sea, 1960-2005. Prog. Oceanogr. 73, 242-276. doi:10.1016/j.pocean.2007.04.015.

Yashayaev, I., Loder, J.W., 2009. Enhanced production of Labrador Sea water in 2008. Geophys. Res. Lett. 36, L01606. doi:10.1029/2008GL036162.

Yu, L., Weller, R.A., Sun, B., 2004. Improving latent and sensible heat flux estimates for the Atlantic Ocean (1988-1999) by a synthesis approach. J.Clim. 17, 373-393. 